\title{
Sea-Borne Tourism in Antarctica: Avenues for Further Intergovernmental Regulation
}

\author{
Erik Jaap Molenaar* \\ Netherlands Institute for the Law of the Sea (NILOS), \\ Utrecht University \& \\ Institute of Antarctic and Southern Ocean Studies (IASOS), \\ University of Tasmania
}

\begin{abstract}
During the past 3,5 decades, sea-borne (cruise) tourism in Antarctica has steadily intensified and diversified. So far, the States involved in the Antarctic Treaty System (ATS), who have collectively assumed a mandate as well as a responsibility for governing Antarctica, have been relatively passive as a collective and have largely relied on direct and indirect regulation from outside the ATS, most importantly on self-regulation by the tourism industry through the International Association of Antarctica Tour Operators (IAATO). In view of the gradual intensification and diversification of Antarctic tourism, the abovementioned responsibility of the Consultative Parties to the Antarctic Treaty (ATCPs) and the need to safeguard the international legitimacy of the ATS, this article examines avenues for further international regulation by the ATCPs. This is in part done by exploring the meaning of the acronym IUU (illegal, unreported and unregulated) in the sphere of Antarctic sea-borne tourism, to what extent it occurs and how some forms can be addressed.
\end{abstract}

\section{Introduction}

Tourism is in certain respects the largest global industry. ${ }^{1}$ Statistics of the World Travel and Tourism Council (WTTC) indicate that in 2004 world tourism and travel (direct and indirect) employs 214.7 million people and accounts for US\$ 5.5 trillion of economic value (GDP), representing 10.4 per cent of global GDP. ${ }^{2}$ Whereas the WTTC predicts continuous growth in the next decade, ${ }^{3}$ global unrest caused for instance by terrorist activities or transnational

* Email: E.Molenaar@law.uu.nl. The author is indebted to K. Bastmeijer, A.D. Hemmings, N. Kennedy, L. Kriwoken, D. Landau, C. Murray, W. Papworth and M. Richardson for providing information or comments on an earlier version of this article. The author remains entirely responsible for the current text.

1 Cf. Tourism and Biodiversity. Mapping Tourism's Global Footprint (Conservation International: 2003; text at $<w w w . c o n s e r v a t i o n . o r g>)$, at pp. $\mathrm{v}$ and 1.

2 Progress and Priorities 2004/05, at p. 15; text at <www.wttc.org $>$.

Ibidem.

THE INTERNATIONAL JOURNAL OF MARINE AND COASTAL LAW, Vol 20, No 2 (C) Koninklijke Brill NV, 2005 
diseases can obviously not be factored in. The tremendous expansion in international tourism in the second half of the 20th century is particularly evident in the cruise ship industry. Since 1980 that industry has had an annual growth rate of 8.4 per cent; nearly twice as fast as world international tourist arrivals over the past decade. ${ }^{4}$ All indications are for that growth to continue in the near future. ${ }^{5}$

Prior to the austral summer of 1990-91, the number of tourists that participated in Antarctic sea-borne tourism did not rise above 4,000 and oscillated in many years around $1,000 .{ }^{6}$ Between $1990-91$ and 2002-03, tourist numbers steadily increased from around 4,700 to 15,800 , while around 2,400 of the latter figure were tourists on large cruise vessels that offered no landings. ${ }^{7}$ The 2003-04 austral summer witnessed a spectacular increase as an estimated 24,318 tourists participated in sea-borne tourism, with an estimated 4,949 of these not making landings. ${ }^{8}$ A further increase took place during 2004-05, with an estimated 27,324 sea-borne tourists of which 5,027 did not make landings. For the 2005-06 season, the preliminary estimates are 31,287 and 4,700 respectively. ${ }^{9}$ In a global perspective, however, Antarctic tourism is obviously still a relatively small niche market.

Sea-borne Antarctic tourism raises a number of concerns. Some of these are inspired by notorious incidents with navigation in high latitudes in the Northern Hemisphere, such as the sinking of the Titanic after a collision with an iceberg during her maiden trans-Atlantic crossing to New York in 1912 and the grounding of the Exxon Valdez in Prince William Sound, Alaska, in 1989. Until now, by far the most serious accident in Antarctica has been with airborne tourism due to the crash of an Air New Zealand DC10 on Mount Erebus in 1979. All of the 257 crew and passengers died. Fortunately, Antarctic shipping, whether for tourism or other purposes, has not yet seen human or environmental tragedies on a Titanic or Exxon Valdez scale. The largest maritime disaster in Antarctic so far occurred in 1989 when the Argentinean navy ship Bahía Paraiso struck rocks and sank near the United States Palmer Station on the Antarctic Peninsula, spilling a large amount of fuel.

The risk of a major human or environmental tragedy happening in Antarctica is difficult to assess. On the one hand, vessel-construction, navigation technology and safety and environmental protection standards and regimes

4 Cf. Tourism and Biodiversity, note 1, at p. 31.

5 Cf. D. Johnson, "Environmentally Sustainable Cruise Tourism: A Reality Check", 26 Marine Policy 261-270 (2002), at p. 262 and the info at the website of the International Council of Cruise Lines (ICCL) at <www.iccl.org $>$.

6 Based on P.J. Tracey, Managing Antarctic Tourism, unpublished PhD thesis (University of Tasmania, Institute of Antarctic and Southern Ocean Studies: April 2001), at p. 48.

7 Based on Tracey, note 6, at p. 48 and on Doc. ATCM XXVII/IP/63 (2004) 'IAATO Overview of Antarctic Tourism 2003-2004 Antarctic Season', at p. 4. These numbers do not include tourists on government vessels, those participating in government-sponsored tourism and tourists on yachts.

8 Doc. ATCM XXVII/IP/63, note 7 , at p. 17 .

9 Doc. ATCM XXVIII/IP/82 (2005) 'IAATO Overview of Antarctic Tourism. 2004-2005 Antarctic Season', at pp. 3 and 23. 


\section{ANTARCTIC TOURISM AND FURTHER INTERGOVERNMENTAL REGULATION 249}

have greatly improved since the disasters of the Titanic and also the Exxon Valdez. On the other hand, the special characteristics of Antarctica enhance risks. These characteristics include its remoteness, the harshness of its climate, the often difficult navigation conditions, extensive areas that are poorly charted and the vulnerability of its ecosystem. In addition, and this is the principal focus of this article, the regulation of all human activities in Antarctica and its surrounding waters is weakened by the absence of undisputed sovereignty over the Antarctic continent. The agreement to disagree on the question of sovereignty as laid down in Article IV of the Antarctic Treaty ${ }^{10}$ precludes the exercise of unilateral jurisdiction over the continent and adjacent maritime areas. ${ }^{11}$ The regulation of human activities on the Antarctic continent and in its adjacent maritime areas therefore has many similarities with that of the high seas, whose regime relies on the freedom of the high seas and the primacy of flag State jurisdiction..$^{12}$ In view of this similarity, a 'tragedy of the commons' in Antarctic tourism cannot be ruled out. Assessing the likelihood for this to happen is obviously very difficult. While the large cruise ships that are increasingly being used in Antarctic waters despite their lack of ice-strengthening are often singled out in this discussion, ${ }^{13}$ it is certainly not evident that they pose the highest risks.

International regulation of Antarctic sea-borne tourism is certainly not absent. However, the States involved in the Antarctic Treaty System (ATS), who have collectively assumed a mandate as well as a responsibility for governing Antarctica, have so far been relatively passive as a collective. It is nevertheless acknowledged that various ATCPs (Antarctic Treaty Consultative Parties) have been very active in regulation at the national level. ${ }^{14}$ The focus

10 The Antarctic Treaty, Washington D.C., 1 December 1959. In force 23 June 1961, 402 United Nations Treaty Series 71; <www.antdiv.gov.au>.

11 Territorial jurisdiction would not even be an option for the unclaimed sector of the Antarctic continent.

12 Cf. Arts 87-92 of the LOS Convention (United Nations Convention on the Law of the Sea, Montego Bay, 10 December 1982. In force 16 November 1994, 1833 United Nations Treaty Series 396; <www.un.org/Depts/los>).

13 See inter alia Doc. ATME 2004 (Antarctic Treaty Meeting of Experts on Tourism and NonGovernmental Activities in Antarctica, Tromsø-Trondheim, March 2004) No. 7 'An Analysis of the Existing Legal Framework for the Management of Tourism and Non-Governmental Activities in Antarctica. Issues, Some Proposals and Comments. Paper submitted by New Zealand', at p. 3, where it is also claimed that these vessels do not have crews with the necessary skills for ice-navigation. However, the cruise vessels operated by the Holland America Line (HAL) always use ice-pilots during navigation in Antarctic waters. The time spent in Antarctic waters is limited to 2-3 days per cruise (information provided by C. Deelstra, HAL, April 2004). See also Doc. ATCM XXVI/WP/23 (2003) 'Proposals to Improve the Management and Regulation of Antarctic Tourism. Submitted by the United Kingdom', at p. 6, where it is also observed that larger vessels are "more likely to be fuelled by heavy bunker fuel oil carried in much greater quantities"; and ATCM Resolution 6 (1999) 'Adherence to the Environmental Protocol by Non-Consultative Parties'. See also notes 77 and 203.

14 For a thorough analysis of the legislation of several States see K. Bastmeijer, The Antarctic Environmental Protocol and its Domestic Legal Implementation (Dordrecht Kluwer Law International: 2003). 
of this article is on the international level, however, and at this level the States involved have largely relied on direct and indirect regulation from outside the ATS, most importantly on self-regulation by the tourism industry through the International Association of Antarctica Tour Operators (IAATO).

In view of this strong reliance on industry self-regulation as well as the absence of unilateral (territorial) jurisdiction in Antarctica, this article examines the acronym IUU (illegal, unreported and unregulated) in the sphere of Antarctic sea-borne tourism. The acronym has originated in the international regulation of marine capture fisheries to denote various problems that undermine the effectiveness of national and international regulation aimed at sustainable fisheries and biodiversity conservation..$^{15}$ This article examines the meaning of IUU sea-borne tourism in Antarctica, to what extent it occurs and which avenues are open for addressing it.

The two following sections contain some factual information on the development and nature of Antarctic tourism and the risks associated with Antarctic sea-borne tourism. The focus is exclusively on commercial tourism. ${ }^{16}$ No or little attention is given to tourists on government vessels, those participating in government-sponsored tourism and small-scale private expeditions, for instance those using yachts.

The subsequent section provides an overview of current international regulation of Antarctic sea-borne tourism. Whereas the first subsection examines regulation within the ATS, the second subsection examines current regulation outside the ATS. The definition of the ATS that is incorporated in Article 1(e) of the Protocol on Environmental Protection to the Antarctic Treaty (Madrid Protocol) $)^{17}$ is used as a point of departure..$^{18}$ But as strict adherence to this definition is unnecessary for the purpose of this article, the acronym ATS is treated as encompassing a broader range of instruments. These include the

15 See, for instance, the IPOA on IUU Fishing (International Plan of Action to Prevent, Deter and Eliminate Illegal, Unreported and Unregulated Fishing. Adopted by consensus by the United Nations (UN) Food and Agriculture Organisation (FAO) Committee on Fisheries on 2 March 2001 and endorsed by the FAO Council on 23 June 2001; text at <www.fao. org/fi $>$ ).

16 The UN Statistical Commission describes tourism as "the activities of persons traveling to and staying in places outside their usual environment for not more than one consecutive year for leisure, business and other purposes not related to the exercise of an activity remunerated from within the place visited" (see inter alia Doc. ST/ESA/STAT/SER.M/83/Rev.1 of 27 December 1999, at p. 4, para. 1.6). See also the distinction between commercial tourism and non-governmental non-tourist expeditions in the Handbook of the Antarctic Treaty System, (U.S. Department of State, 9th ed., 2002; text at <www.state.gov/g/oes/rls/rpts/ant/>), at p. 297.

17 Madrid, 4 October 1991 (Annexes I-IV). In force 14 January 1998, 30 International Legal Materials 1455 (1991); Annex V, Bonn, 17 October 1991. In force 24 May 2002, adopted as ATCM Recommendation XVI-10 (1991); Antarctic Treaty Handbook, note 16, at pp. $18-65$.

18 On the acronym see also D. Vidas, "The Antarctic Treaty System in the International Community: An Overview", in O.S. Stokke and D. Vidas (eds.) Governing the Antarctic. The Effectiveness and Legitimacy of the Antarctic Treaty System (Cambridge, University Press: 1996), pp. 35-60, at pp. 37-39. 
Antarctic Treaty, the Recommendations, Measures, Decisions and Resolutions made by Antarctic Treaty Consultative Meetings (ATCMs), ${ }^{19}$ the Madrid Protocol, the CCAS, ${ }^{20}$ the CCAMLR Convention ${ }^{21}$ and the Conservation Measures and Resolutions adopted by CCAMLR (Commission for the Conservation of Antarctic Marine Living Resources). The CRAMRA, ${ }^{22}$ which is not expected to ever enter into force, is here also regarded as part of the ATS.

International regulation outside the ATS comprises regulation by 'external' intergovernmental organizations (IOs), most importantly IMO (International Maritime Organization) and international industry non-governmental organizations (NGOs) such as IAATO.

As tourism is regarded as a purpose for which particular activities are undertaken, a distinction is made between so-called direct and indirect international regulation of Antarctic sea-borne tourism. Direct regulation is used to refer to the regulation of tourism or sea-borne tourism in general; as a purpose therefore. Indirect regulation, on the other hand, is used to refer to the essentially sectoral regulation of specific activities undertaken during tourism. The main example here is shipping. Unless indicated otherwise, regulation is used in this article in a very broad sense, encompassing both legally binding and non-legally binding forms and including industry self-regulation.

The two sections thereafter discuss the international legitimacy of the ATS and IUU sea-borne tourism in Antarctica. The article ends with some conclusions and observations.

\section{Development of Antarctic Sea-Borne Tourism}

While some commercial tourism predates the adoption of the Antarctic Treaty in 1959, modern commercial tourism is widely regarded as having started in 1970, when the purpose-built cruise-vessel MS Lindblad Explorer began operating. ${ }^{23}$ 'Expedition-cruising', pioneered by Lars Eric Lindblad, is probably still the predominant form of Antarctic sea-borne tourism today. The

19 Reference is made to ATCM Decision 1 (1995) 'Measures, Decisions and Resolutions' and to Doc. ATCM XXVII/IP/36 (2004) 'Report of the Depositary Government of the Antarctic Treaty (USA) in accordance with Recommendation XIII-2', which gives in Annex 3 an overview of the status of Recommendations and Measures pursuant to Art. IX(4) of the Antarctic Treaty.

20 Convention for the Conservation of Antarctic Seals, London, 1 June 1972. In force 11 March 1978, 11 International Legal Materials 251; Antarctic Treaty Handbook, note 16, at pp. 332-334.

21 Convention on the Conservation of Antarctic Marine Living Resources, Canberra, 20 May 1980. In force 7 April 1982, 19 International Legal Materials 837 (1980); <www.ccamlr. org $>$.

22 Convention on the Regulation of Antarctic Mineral Resource Activities, Wellington, 2 June 1988. Not in force, 27 International Legal Materials 868 (1988); Antarctic Treaty Handbook, note 16 , at pp. 385-431.

23 Cf. R. Headland, "Historical Development of Antarctic Tourism", 21 Annals of Tourism Research 269-280 (1994), at p. 276 and L.K. Kriwoken and D. Rootes, "Tourism on Ice: Environmental Impact Assessment of Antarctic Tourism”, 18 Impact Assessment and Project Appraisal $138-150$ (2000), at p. 140. 
'expedition mode' of operation means that the cruise-schedule is constantly adjusted to the sea, wind, ice and weather conditions, the abilities and interests of passengers and the schedules of other cruise vessels in the area. ${ }^{24} \mathrm{Key}$ attractions of Antarctic tourism include viewing a broad range of scenic features and iconic wildlife, scientific stations and historic Antarctic exploration sites. Antarctic sea-borne tourism takes mainly place during the austral summer between late October and the middle of March, due to limited ice-coverage, the presence of more wildlife during breeding seasons, longer daylight and higher temperatures.

The steep increase in tourist numbers in the late 1980s was to some extent a consequence of the campaigns by environmental NGOs for enhanced environmental protection of Antarctica. ${ }^{25}$ The industry also experienced a significant expansion in the wake of the collapse of the Soviet Union, which meant that many icebreakers and other vessels suitable for navigation in polar waters became available for charter. ${ }^{26}$ As already noted, tourist numbers have increased since and further increases are forecast. This also applies to large-scale airborne tourism in Antarctica, which resumed in 1994-95. This is currently mainly limited to 'flight-seeing' (but see below).

Three other developments related to Antarctic sea-borne tourism must be noted. First, while Antarctic air-borne tourism may grow considerably, seaborne tourism is still expected to remain predominant. The 2001 decision by IAATO to also offer full membership to tour operators using vessels with a capacity of 400 passengers and more illustrates that the composition of the fleet is changing. ${ }^{27}$ However, it is difficult to predict the relative importance of cruises offering landings versus cruises offering no landings in the near future. Second, the type of available tourist activities has diversified over the years. In addition to flight and sightseeing (without landings), small boat or Zodiac cruising and short (1-3 hours) landings, some tour operators also offer kayaking, scuba diving, mountain climbing, ski-activities, camping, marathon running and helicopter operations..$^{28}$ Third, the 2003-04 season saw the first 'fly-cruise' where tourists were flown to King George Island in the Antarctic Peninsula

24 Cf. Tracey, note 6, at pp. 50 and 53 and A.D. Hemmings and R. Roura, "Antarctic Tourism. A Square Peg in a Round Hole: Fitting Impact Assessment under the Antarctic Environmental Protocol to Antarctic Tourism", 21 Impact Assessment and Project Appraisal 13-24 (2003), at p. 19.

25 Cf. A.D. Hemmings, "Antarctica in Transition", Forest \& Bird Issue No. 284, pp. 38-44 (1997), at p. 44 and M.G. Richardson, "Regulating Tourism in the Antarctic: Issues of Environment and Jurisdiction" in D. Vidas (ed.) Implementing the Environmental Protection Regime for the Antarctic (Dordrecht, Kluwer Academic Publishers: 2000), pp. 71-90, at p. 73.

26 Cf. Doc. ATCM XXIV/IP/40 (2001) 'Antarctic Tourism' (ASOC (The Antarctic and Southern Ocean Coalition)).

27 See Art. III of the IAATO Bylaws, text at $<$ www.iaato.org $>$. See also note 105 and accompanying text and the discussion by Bastmeijer, note 14, at pp. 281-282.

28 See also K. Bastmeijer, "Tourism in Antarctica: Increasing Diversity and the Legal Criteria for Authorisation", 7 New Zealand Journal of Environmental Law 85-118 (2003), at pp. 89-91. 
region to board a vessel. ${ }^{29}$ For many tourists, flying to Antarctica is attractive as it is more comfortable and much quicker than by ship. In addition to attracting a broader market, shorter cruises would also enable tour operators to offer more cruises per season. More runways are expected to become operational in Antarctica soon, ${ }^{30}$ and if these were to become available for tourism, fly-cruises could lead to significant increases in tourist numbers and could also change the nature and impacts of Antarctic tourism in general.

Most (95\% and higher) of Antarctic sea-borne tourism is concentrated in the region of the Antarctic Peninsula, with longer cruises also including the Falklands/Malvinas, South Georgia or other regional sub-Antarctic islands in their itinerary. By far the main so-called gateway port is Ushuaia (Argentina). While Punta Arenas (Chile) and Stanley (Falklands/Malvinas) service most of the remainder of the expedition-style cruises, Valparaiso (Chile), Puerto Madryn and Buenos Aires (Argentina) and Rio de Janeiro (Brazil) are mainly important for the large cruise liners. ${ }^{31}$ All these ports are used for provisioning (fuel, food, water etc.), for processing waste and as semi-permanent bases for (dis-)embarking passengers and crew. Puerto Williams (Chile) is well-situated practically across the Beagle Channel from Ushuaia but its facilities and infrastructure are far from adequate. The remaining $5 \%$ or so of Antarctic seaborne tourism focuses mainly on the Ross Sea area. Lyttelton and Bluff (New Zealand) and Hobart (Australia) are used for (dis-)embarking and provisioning and most itineraries include visits to one or more sub-Antarctic islands to break the much longer journey to the continent. These are Macquarie Island (Australia) and Antipodes, Auckland and Campbell Islands (New Zealand). ${ }^{32}$

Effective control by the United Kingdom over the Falkland Islands, South Georgia and the South Sandwich Islands ${ }^{33}$ and uncontested sovereignty by other States over their sub-Antarctic islands offer the possibility of regulation based on territorial, port and coastal State jurisdiction. As visits to these islands are often combined with visits to Antarctica, this also enables some indirect regulation of tourism on the Antarctic continent. ${ }^{34}$ The exercise of port State jurisdiction by gateway ports offers these possibilities as well.

29 See Doc. ATCM XXVII/IP/63, note 7, at pp. 2, 10, and 12. In 2004-05, the Chilean operator Antarctica 21 used the Grigory Mikheev, flagged in the Russian Federation. In 2005-06, the Aleksey Maryshev, flagged in the Russian Federation, will be used (Doc. ATCM XXVIII/IP/82, at p. 20). It is worth noting however, that Headland, note 23, at p. 276 observes that both Argentina and Chile used "their air strips, on Seymour Island and King George Island, respectively" for fly-cruises prior to 1994 (when that article was published).

30 For instance the plans by Australia for an intercontinental air service between Hobart and a graded blue-ice runway $50 \mathrm{~km}$ from Casey Station, commencing in 2004/05 (21 AntArctic Issues Nos. 186 and 187, p. 69; 6 Australian Antarctic Magazine 53-54 (Autumn 2004)). See also Doc. ATCM XXVII/IP/50 (2004) 'International Project on the Cooperative Air Network in East Antarctic "DROMLAN" (Russian Federation)'; and Doc. ATCM XXVII/IP/35 (2004) 'Initial Environmental Evaluation for Troll Runway (Norway)'.

31 See Doc. ATCM XXVII/IP/63, note 7, at p. 4.

32 No landings are allowed on Antipodes Islands.

33 Argentina also claims sovereignty over these islands and over Shag Rocks.

34 For instance, as sea-borne visits to the Ross Sea area are unattractive unless combined with visits to Macquarie Island and New Zealand's sub-Antarctic islands, the relatively few permits 
Also worth noting is that at the time of writing Argentina still blocked the resumption of charter-flights from Punta Arenas to Stanley, either by not granting LAN Chile access to Argentine airspace or by not granting it landing rights in the Islas Malvinas (Falklands). This has (further) marginalized Stanley's role as gateway port to the Antarctic and enhanced that of Ushuaia. Whether or not inspired by these Argentine actions, Chile prohibits landings on Cape Horn and since 2004 also lateral passage within 12 nautical miles of Cape Horn, unless vessels have a pilot on board that is picked up from Puerto Williams. As landings on and cruising close to Cape Horn were normally planned on the return journey from the Antarctic Peninsula, the latter condition is very problematic. In fact, the consistency of the prohibition of lateral passage with the right of innocent passage under Article 17 of the LOS Convention is very questionable. A significant shift towards fly-cruising is likely to diminish the relative influence of Ushuaia while Punta Arenas, other gateway ports and even Cape Town may gain influence. This would among other things necessitate a re-orientation of jurisdictional bases.

\section{Nature of Antarctic Sea-Borne Tourism}

There are several important distinctions between sea-borne tourism in general and that in Antarctica. First, apart from personnel at government stations, Antarctica does not have an indigenous population. Second, there is currently virtually no purpose-built land-based infrastructure for tourism on the Antarctic continent. This appears unlikely to change in the near future. ${ }^{35}$ Some tour operators (occasionally) use certain facilities at government stations and there is a tentbased summer camp at Patriot Hills in the interior (Ellsworth Mountains), which is dismantled at the end of each summer season. ${ }^{36}$ This second distinction with sea-borne tourism in general has important operational and logistical implications as the Antarctic continent can in general not be used for provisioning or for storage or processing of waste. ${ }^{37}$ While such difficulties may be even more prevalent for fly-cruises, these may be outweighed by the financial gains. A third distinction has already been mentioned, namely that the larger cruise vessels may not offer landings.

It is submitted that rather than regarding tourism as an activity per se, it should be regarded as a purpose for which particular activities are undertaken. ${ }^{38}$ Under the international law of the sea, it is often difficult to distin-

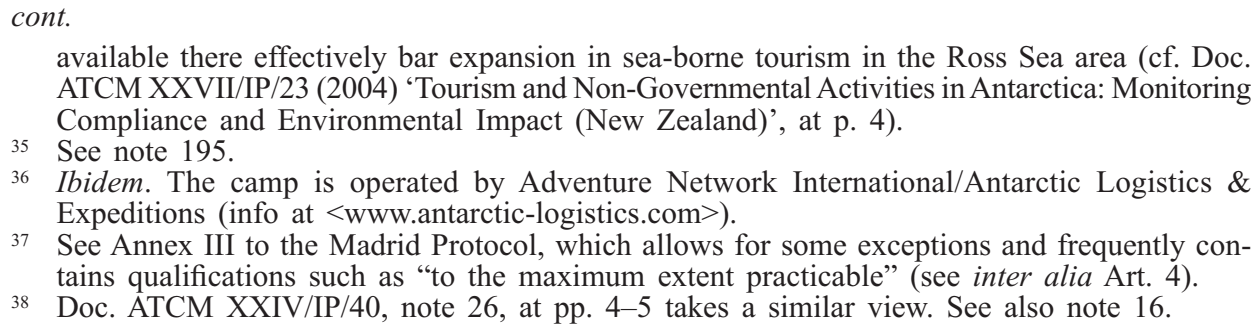

36 Ibidem. The camp is operated by Adventure Network International/Antarctic Logistics \& Expeditions (info at <www.antarctic-logistics.com $>$ ).

37 See Annex III to the Madrid Protocol, which allows for some exceptions and frequently contains qualifications such as "to the maximum extent practicable" (see inter alia Art. 4).

38 Doc. ATCM XXIV/IP/40, note 26, at pp. 4-5 takes a similar view. See also note 16. 
guish sea-borne tourism from the activity of navigation. However, certain resourcerelated activities in which a vessel engages during navigation are nevertheless generally accepted as being independent from the activity of navigation, for instance fishing and probably also whalewatching. While the former example is a form of resource exploitation (consumption), the latter is a non-consumptive use of living resources that nevertheless requires regulation to avoid or mitigate certain risks. While viewing the Antarctic wilderness from aboard a ship can also be regarded as a non-consumptive use of resources, the resource in this case being Antarctica, for regulatory purposes it is not likely to be treated distinct from the activity of navigation. The industry certainly intends Antarctic sea-borne tourism to be a non-consumptive use of Antarctica. The recreational fishing activities which may occasionally occur do not affect that intention. It is nevertheless clear that the regulation of Antarctic sea-borne tourism is required to avoid or mitigate certain risks. Some may even regard the operational impacts of tourist vessels, for instance discharges and emissions of pollutants, or even the mere presence of such vessels in view of the wilderness and aesthetic values of Antarctica, as a form of consumption (see below).

The need to determine whether or not an activity is an independent one is relevant in marine areas where coastal State jurisdiction is not disputed. In these areas coastal States can regulate certain activities (unilaterally or in accordance with internationally agreed regulation) or prohibit them altogether. As a consequence of the unique sovereignty situation in Antarctica, no State can unilaterally regulate or prohibit activities by foreign vessels or other nationals (natural and juridical persons). The principal exception to that general rule would be landings at or close to government stations. ${ }^{39}$ The regulation of sea-borne tourism in Antarctica, whether by large cruise liners in transit or by vessels that anchor and deploy landing parties, is therefore not governed by territorial or coastal State jurisdiction. Rather, the regulatory regime consists of a complex web of concurrent (overlapping) international regimes, each of which contains principles, rights and obligations for groupings of States with varying compositions. This characterization conveniently avoids difficult questions as to the legal status of the Antarctic continent and its adjacent waters. In this complex web of regimes, the regulation of sea-borne Antarctic tourism relies predominantly on flag State jurisdiction, ${ }^{40}$ the notion of the freedom of the high seas and the core elements and objectives of the Antarctic Treaty.

39 Cf. Richardson, note 25, at p. 84. This authority is implied in ATCM Recommendation XVIII-1 (1994) 'Tourism and Non-governmental Activities', Attachment A 'Guidance for Visitors to the Antarctic', at C(1) and 'Guidance for those Organising and Conducting Tourism and Non-governmental Activities in the Antarctic', at B(2) and in ATCM Recommendation VIII9 (1975) 'Effects of Tourists and non-Governmental Expeditions in the Antarctic Treaty Area', at No. 3 and Annex A.

40 But see Art. VII(5) of the Antarctic Treaty. 
The Madrid Protocol is regarded by many as adding a third pillar (or objective or principle), of environmental protection, to the two original pillars of the Antarctic Treaty: freedom of scientific investigation and using Antarctica for peaceful purposes. ${ }^{41}$ There is no separate pillar of, say, freedom of (sustainable) tourism. However, viewed as a purpose rather than an activity per se, tourism is not at odds with any of these three pillars. ${ }^{42}$ In fact, tourism has been treated as a "natural development", ${ }^{43}$ as one of the "established uses of Antarctica" 44 and as a legitimate activity due to explicit references to "tourism" in the Madrid Protocol. ${ }^{45}$ This is in line with the World Tourism Organization (WTO) Global Code of Ethics for Tourism ${ }^{46}$ which lays down in Article 7, entitled 'Right to tourism' the principle that "The prospect of direct and personal access to the discovery and enjoyment of the planet's resources constitutes a right equally open to all the world's inhabitants (...)". ${ }^{47}$ With regard to the marine dimension, Antarctic tourism can rely on the freedom of the high seas and the primacy of flag State jurisdiction. For the terrestrial dimension, Antarctic tourism can rely on the freedom of access that is derived from the disputed territorial sovereignty in Antarctica and the absence of provisions on general access in the Antarctic Treaty. It should be noted, however, that these explicit or implicit freedoms of access are subordinate to the three pillars of the Antarctic Treaty and implementing regulation as well as the abovementioned restrictions on access to government stations and their immediate terrestrial and marine vicinity.

Striving for sustainable tourism generally requires the balancing of economic, social and ecological interests, for the present as well as for the future. ${ }^{48}$ Striking the sustainability balance in such a way that benefits all interests is unlikely to ever be possible. However, the absence of an indigenous population in Antarctica means that the social component in sustainable Antarctic tourism is relatively insignificant. Also, as most Antarctic sea-borne tourism is nature-based tourism or ecotourism, it has a clear medium and longterm interest in protecting its own resource. But like so many industries that

41 Cf. Arts I and II of the Antarctic Treaty and Art. 2 of the Madrid Protocol. See Vidas, note 18 , at p. 44. It is submitted that even though scientific research is an international community's interest, it is subordinate to the other two pillars.

42 Art. I(1) of the Antarctic Treaty. But see note 195 and accompanying text.

43 See, for instance, the Preamble to ATCM Recommendation VIII-9 (1975), note 39.

44 Art. 15(1) of the CRAMRA.

45 See note 66. R.A. Herr, "The Changing Roles of Non-Governmental Organisations in the Antarctic Treaty System" in Stokke and Vidas, note 18, pp. 91-110, at p. 105 observes that "The Consultative Parties have formally acknowledged the validity of Antarctic tourism as an activity at least since 1971 ”.

46 Adopted by WTO Assembly Resolution A/RES/406(XIII), 1 October 1999, text at <www. world-tourism.org/projects/ethics $>$.

47 Para. (1). See also Art. 8(1), which emphasizes the need for compliance with national and international law.

48 Cf. paras 67-70 of UNGA Resolution A/RES/S-19/2, of 19 September 1997 and the Preamble and Art. 3 of the WTO Global Code of Ethics for Tourism. 
rely on the natural environment, these medium and long-term interests must be balanced against the short-term interest in financial profitability or even cost-recovery.

Some may have difficulty with the goal of sustainability in Antarctic tourism for the reason that it assumes the legitimacy of Antarctic tourism and thereby that at least a certain level of tourism activity should be allowed. But after more than three decades of commercial tourism in Antarctica it would be unrealistic, unfair and almost certainly also unnecessary to ban all tourism. Especially with other potentially more harmful human activities in Antarctica continuing unabated. The notion of sustainability also does not exclude prohibiting certain activities everywhere or all activities in certain areas. The next section demonstrates that the objective of sustainability in Antarctic sea-borne tourism requires more than balancing economic interests against ecological risks. ${ }^{49}$

\section{Risks Associated with Antarctic Sea-Borne Tourism}

A discussion of these risks can be structured in various ways. Here, a choice is made to distinguish first between types of risks and subsequently discuss types of activities in relation to these risks. It is submitted that the most important risks relate to human safety, the Antarctic ecosystem, ${ }^{50}$ Antarctic cultural heritage, interference with other Antarctic activities and certain Antarctic values. The main sea-borne activities that carry these risks are shipping, operating small vessels, such as inflatable boats and kayaks, scuba-diving and snorkeling.

Human safety risks of shipping include exposure to extreme weather and sea-conditions that threaten the stability and integrity of the vessel, groundings and collisions with other vessels or objects such as icebergs and growlers (chunks of older, hard ice that float practically entirely under the water-surface). Collisions with the latter objects pose a special hazard to ships that are not ice-strengthened. Moreover, the risk of grounding or collisions with rocks seems particularly high for Antarctic waters as these are often poorly charted. ${ }^{51}$ Small vessels are also exposed to these risks and to others, for instance waves caused by the toppling of icebergs or chunks of ice-shelves breaking off and

49 See also the Australian Policy on Antarctic Tourism by which "The Australian Government recognises the legitimacy of tourism activities in Antarctica provided they further the principles and objectives of the Antarctic Treaty and their conduct is ecologically sustainable and socially responsible" (Doc. ATME 2004 No. 17 "An Analysis of Potential Threats and Opportunities Offered by Antarctic Tourism. Submitted by Australia', Attachment A).

50 This term is not used or defined in any of the instruments of the ATS but is inspired by the broadly-defined terms 'Antarctic marine ecosystem' and 'Antarctic marine living resources' in Art. I(2) and (3) of the CCAMLR Convention.

51 See inter alia ATCM Resolution 3 (2003) 'Co-operation in Hydrographic Survey and Charting of Antarctic Waters' and Doc. ATCM XXVII/WP/30 (2004), 'Report by the International Hydrographic Organization (IHO) on "Cooperation in Hydrographic Surveying and Charting of Antarctic Waters"'. 
falling into the water. When these vessels are used for viewing marine wildlife, especially the larger species, the vessels may be susceptible to physical contact and thereby instability. Encounters with marine wildlife during scuba diving or snorkeling, whether intentional or not, have obvious human safety concerns. One of the consequences of the human safety risks associated with sea-borne Antarctic tourism is the need for search and rescue (SAR) capability. This aspect is discussed further below.

The risks to the Antarctic ecosystem posed by the various sea-borne activities include:

- shipping incidents leading to accidental discharges of polluting substances (predominantly bunker fuel) or physical impact on the marine ecosystem (e.g. whale-strikes);

- navigation impacts (noise pollution ${ }^{52}$ and other forms of impacts on or interference with marine species potentially causing, for instance, disruption of behavior, abandonment or trampling of the young by fleeing animals or displacement from normal habitat);

- operational impacts (fuel leakages, ${ }^{53}$ discharge of fuel residues [sludge], vessel-source air pollution and the introduction of alien organisms through ballast-water exchanges or attachment to vessel hulls [e.g. in crevices] ${ }^{54}$ );

- waste management impacts (garbage, sewage and incineration of waste); and

- in a few locations, like Port Foster, ${ }^{55}$ anchoring impacts.

Activities that are not strictly sea-borne also have many ecosystem risks, inter alia, due to harmful interference with Antarctic flora (e.g. trampling of mosses, lichens and microbial communities ${ }^{56}$ ) and fauna, trampling effects on ground forms, soil erosion, the translocation of endemic species and the accidental introduction or translocation of alien species, parasites and diseases..$^{57}$

Once tourists are landed and visit, for instance, Historic Sites and Monuments (HSMs; e.g. historic huts), sea-borne tourism also brings along cultural heritage risks. Sea-borne tourism can also interfere with other Antarctic activities, such as fisheries, bioprospecting, shipping for other purposes and scientific research, including supporting operations. In the future, new resource and non-resource activities may be affected by tourism as well, for instance

52 See inter alia Doc. ATCM XXVII/IP/56 (2004) 'An Update on Some Issues Surrounding Noise Pollution' (ASOC).

53 See inter alia Doc. ACTM XXVI/IP/117 (2003) 'Coastal Sediment Pollution at Sites Frequently Visited by Tourism Operations' (ASOC).

54 See Doc. ATME 2004 No. 14 'Establishment of Effective Antarctic Quarantine Controls for Tourism and Non-Government Activities. Submitted by Australia', at p. 2; and Final Report of the XXVIIth ATCM (2004), at p. 23, para. 134, which inter alia refers to the fact that many vessels used in Antarctic tourism also operate in the Arctic.

55 Information provided by M. Richardson, 8 September 2004.

56 Tracey, note 6 , at p. 114 .

57 According to Doc. ATME 2004 No. 17, note 49, at p. 1, this has the highest priority for Australia. 
harvesting seals ${ }^{58}$ or icebergs. Whereas commercial whaling per se is currently the subject of the general worldwide moratorium adopted by the International Whaling Commission (IWC), commercial whaling in Antarctic waters is also limited by the IWC's establishment of the Southern Ocean Sanctuary. Despite these two layers of regulation, Japan is presently still entitled to engage in scientific whaling using lethal techniques on minke whales in the Southern Ocean Sanctuary. The qualification of this activity as scientific research is often questioned.

Article 3(1) of the Madrid Protocol stipulates that among the "fundamental considerations in the planning and conduct of all activities in the Antarctic Treaty area" is "its value as an area for the conduct of scientific research, in particular research essential to understanding the global environment". Paragraph (3) takes this a step further by stipulating that "Activities shall be planned and conducted in the Antarctic Treaty area so as to accord priority to scientific research and to preserve" the value mentioned above. Giving scientific research priority over other activities, including tourism, could be seen as an implementation of the fact that scientific research is one of the three pillars of the Antarctic Treaty. ${ }^{59}$ Although no further guidance is given as to how priority should be put into practice, it is certainly not evident that this priority is absolute and that the interests of tourism can always be ignored in all circumstances.

Interference of scientific research by tourism activities in Antarctica could happen on land and offshore and not only in relation to the research activity but also the object of study (e.g. base-line studies). In addition, tourism can cause indirect interference in case of incidents that raise environmental or human safety concerns. The latter is especially relevant for the more risky forms of adventure tourism. If government assistance is needed to address these concerns, for example by means of SAR operations, this may often only be feasible by means of diverting resources intended for research or instead by maintaining SAR capability that is extremely expensive due Antarctica's harsh environment and remoteness. On the other hand, tourist expeditions can often also offer SAR services amongst each other and even to (governmental) scientific expeditions that encounter problems. ${ }^{60}$

Also among the "fundamental considerations in the planning and conduct of all activities in the Antarctic Treaty area" that are listed in Article 3(1) of the Madrid Protocol is "the intrinsic value of Antarctica, including its wilderness and aesthetic values". It has been argued that categorizing wilderness and aesthetic values as intrinsic values is erroneous as the latter values are entirely

58 This would be subject to the CCAS, note 20 .

59 See also note 41.

60 Doc. ATCM XXVI/IP/96 (2003) 'Adventure Tourism in Antarctica' (IAATO), p. 3 gives an example of the latter situation. 
within the human preference system. ${ }^{61}$ The wilderness and aesthetic values of Antarctica are nevertheless important tourist attractions. The visible presence of large numbers of tourists, several cruise vessels simultaneously and noticeable impact (e.g. land-based infrastructure, footsteps, littering), even if merely temporary, affect wilderness and aesthetic values. The tourism industry has in fact a clear interest in safeguarding the formula of expedition-cruising and the perception of Antarctica as a wilderness.

Finally, it would be unfair to focus exclusively on the negative impacts of tourism without also mentioning the positive side. ${ }^{62}$ The already mentioned enhanced SAR capability offered by tourist vessels benefits other tourist and non-tourist activities. Other benefits include commercial rewards, satisfying demand by tourists, creating 'ambassadors for Antarctic conservation and science', ${ }^{63}$ logistic and substantive support for scientific research and even an informal means of monitoring the performance (e.g. environmental or safety) of activities in Antarctica. ${ }^{64}$ As these benefits and the fact that Antarctic tourism is a legitimate activity should be acknowledged, it is only reasonable to also ask the question to what extent other Antarctic activities have an impact on tourism.

\section{Current International Regulation of Antarctic Sea-Borne Tourism}

\section{Regulation by the ATS}

\section{Direct Regulation}

Direct regulation of Antarctic sea-borne tourism by the ATS $^{65}$ currently exists in two main forms. The first is through the Madrid Protocol as it also applies to the activity of tourism. This is indicated by several explicit references to "tourism" 66 as well as general references to "activities",67 and is confirmed,

${ }_{61}$ Tracey, note 6, at p. 37. At the VIIth Meeting of the CEP (Committee for Environmental Protection) (2004), the Czech Republic "noted that the concept of wilderness values is very philosophical and difficult to quantify objectively, and possibly of greater relevance to the consideration of tourism activities" (Final Report of the XXVIIth ATCM (2004), p. 360).

62 See, inter alia, Tracey, note 6, at pp. 119-120.

63 Although P.T. Maher, "Exploring Visitor Experience in the Ross Sea Region, Antarctica", 18 Newsletter for the Canadian Antarctic Research Network 10-11 (2004), at p. 11 questions the actual impact of this. The same position is taken in Doc. ATCM XXIV/IP/40, note 26, at p. 4.

64 See inter alia Doc. ATCM XXVII/WP/30, note 51, and Doc. ATCM XXVII/IP/68 (2004) 'Report of the International Association of Antarctica Tour Operators 2003-2004 under Article III(2) of the Antarctic Treaty', at pp. 10-12 and Appendix D.

65 See the Introduction on the use of the acronym ATS and the distinction between direct and indirect regulation.

66 Arts 3(4), 8(2) and 15(1)(a) of the Protocol and Art. 1(1) of its Annex III. See also Art. 1(1) of Annex I, which implicitly covers tourism due to a cross-reference to Art. 8.

67 See, inter alia, Arts 3 (in its entirety), 6(1) and (3), 8(2), 13(2), (4) and (5), 16 of the Protocol and Art. 1(c) of its Annex V. 
inter alia, by Recommendation XVIII-1 (1994).$^{68}$ It is admitted that this could also be regarded as an indirect form of regulation. However, even though seaborne tourism is covered by the Protocol as such, this does not necessarily mean that actual tourist activities planned or undertaken by natural or juridical persons (e.g. ships and companies) are also subject to its provisions. ${ }^{69}$

The applicability of the Madrid Protocol means that sea-borne tourism is among other things covered by the Protocol's environmental principles, its environmental impact assessment (EIA) procedures (Annex I), provisions on the conservation of Antarctic fauna and flora (Annex II), on waste disposal and waste management (Annex III), on prevention of marine pollution (Annex IV), on response action (including contingency plans) with regard to environmental emergencies, and that tourism can be prohibited or regulated in the various types of special areas under its Annex V. The latter include Antarctic Specially Protected Areas (ASPAs), Antarctic Specially Managed Areas (ASMAs) and HSMs. ${ }^{70}$ Annex IV is discussed in more detail further below.

The second form of regulation is by means of various legally and nonlegally binding instruments adopted by ATCMs that specifically relate to both tourism and other non-governmental activities in the Antarctic Treaty area (south of $60^{\circ}$ South). The most directly relevant are:

- Recommendation XVIII-1 (1994) 'Tourism and Non-governmental Activities';

- Resolution 3 (1995) 'Reporting of Tourism and Non-governmental Activities';

- Resolution 3 (1997) 'Standard Form for Advance Notification and Post-Visit Reporting on Tourism and Non-governmental Activities in Antarctica'; ${ }^{71}$

- Measure 4 (2004) 'Insurance and Contingency Planning for Tourism and Non-governmental Activities in the Antarctic Treaty Area';

- Resolution 3 (2004) 'Tourism and Non-governmental Activities: Enhanced Cooperation amongst Parties'; and

- Resolution 4 (2004) 'Guidelines on Contingency Planning, Insurance and other Matters for Tourist and other Non-governmental Activities in the Antarctic Treaty Area'.

Whereas earlier Recommendations related to tourism ${ }^{72}$ have not been explicitly revoked, Recommendation XVIII-1 (1994) can be regarded as a more comprehensive and updated version of Recommendation VIII-9 (1975). ${ }^{73}$

68 See the 4th Preambular para.

69 See the section 'The Meaning of IUU Sea-Borne Tourism in Antarctica'.

70 See also the info on the various Antarctic protected areas at $<$ www.cep.aq/apa $>$. See, for instance, HSM No. 74 'Wreckage of sailing ship, Elephant Island, South Shetland Islands'.

71 As revised at the XXIVth ATCM (2001) (see Final Report of the XXIVth ATCM (2001), Annex J). See also ATCM Resolution 6 (1999), note 13.

72 These are: IV-27 (1966) 'Effects of Antarctic Tourism; VI-7 (1970), VII-4 (1972), VIII-9 (1975) and X-8 (1979) all entitled 'Effects of Tourists and non-Government Expeditions to the Antarctic Treaty Area' and XI-3 (1981) 'Air Disaster on Mount Erebus'.

73 See note 39 . Cf. Richardson, note 25 , at p. 79. 
Recommendation XVIII-1 (1994) was the outcome of a first attempt to address Antarctic tourism in a more comprehensive manner. The adoption of the Madrid Protocol in 1991 created space on the agenda of ATCMs and the sudden growth in tourism from 1992 onwards generated broad support for regulation. Even though several ATCPs were dissatisfied with the modest outcome in 1994 because they preferred a tourism Annex to the Madrid Protocol, ${ }^{74}$ the attention shifted to other issues, such as the implementation of the Madrid Protocol and the development of an Antarctic environmental liability regime. In 2003, agreement on the Antarctic Treaty Secretariat had been secured and the negotiations on Antarctic environmental liability regime had been redirected towards a less comprehensive and more pragmatic piecemeal outcome. No doubt also as a consequence of already mentioned trends in the Antarctic tourism industry, it was then decided that 'Tourism and Non-governmental Activities' would for the second time feature prominently on the agenda of the next ATCM. ${ }^{75}$

\section{Indirect Regulation}

One of the main sources of indirect regulation of Antarctic sea-borne tourism by the ATS is Annex IV to the Madrid Protocol on prevention of marine pollution. As regards its substantive overlap with MARPOL $73 / 78,{ }^{76}$ it is noteworthy that Annex IV is predominantly concerned with discharge standards. Regulation by means of CDME (construction, design, manning and equipment) standards is left to the discretion of States parties, while taking "into account the objectives of this Annex". ${ }^{77}$ Calls for special requirements for vessel construction became more prominent after developments were under way within IMO on a polar shipping code, ${ }^{78}$ which finally culminated in the 2002 IMO Guidelines for Ships Operating in Arctic Ice-Covered Waters (Arctic Shipping

74 See D. Vidas, "The Legitimacy of the Antarctic Tourism Regime" in Stokke and Vidas, note 18, pp. 294-320, in particular at pp. 307-316; R.A. Herr, "The Regulation of Antarctic Tourism: A Study in Regime Effectiveness", in Stokke and Vidas, note 18, pp. 203-232; and Richardson, note 25 , at pp. 77-79.

75 See inter alia ATCM Decision 5 (2003) 'Meeting of Experts on Tourism and Non-governmental Activities'. See also Doc. ATCM XXIV/IP/40, note 26, which may have played a significant role in setting this process in motion.

76 International Convention for the Prevention of Pollution from Ships (London, 2 November 1973) as modified by the 1978 Protocol (London, 1 June 1978) and as regularly amended. Entry into force varies for each of its Annexes. At the time of writing Annexes I-VI had all come into force. For info see <www.imo.org $>$.

77 Art. 10 of Annex IV. See also Art. 9(1), which could be regarded as an exception. Note also the rather special CCAMLR Resolution 20/XXII (2003) 'Ice-Strengthening Standards in High-Latitude Fisheries' and the New Zealand proposal in Doc. ATME 2004 No. 7, note 13, at p. 3 to have something similar for all commercial tourist vessels operating in the Antarctic Treaty area. See also Doc. ATCM XXVII/WP/42 (2004), 'Fishing Activities: Enhancing Prevention of Marine Pollution (Spain)', which eventually resulted in ATCM Resolution 1 (2004) 'Enhancing Prevention of Marine Pollution by Fishing Activities', which essentially supports CCAMLR Resolution 20/XXII.

78 See ATCM Resolution 3 (1998) 'International Code of Safety for Ships in Polar Waters' and ATCM Decision 2 (1999) 'Guidelines for Antarctic Shipping and Related Activities'. 
Guidelines) $\cdot{ }^{79}$ Following the advice of COMNAP (Council of Managers of National Antarctic Programs) to the XXVIIth ATCM (2004), the Meeting adopted Decision 4 (2004) 'Guidelines for Ships Operating in Arctic and Antarctic IceCovered Waters' which endorses the Guidelines drawn up by COMNAP and requests them to be "transmitted" to IMO with the object of ensuring amendment of the IMO Guidelines to make them specifically applicable to ships in ice-covered waters in the Antarctic Treaty area. Whereas a Decision is not intended to be legally binding and the Preamble actually emphasizes the voluntary nature of the Guidelines, the fact that the Guidelines are endorsed rather than adopted, and also that they are forwarded to IMO, suggests that their current applicability to the Antarctic Treaty area is intended to be less than non-legally binding. Irrespective of previous regulation of shipping through Annex IV to the Madrid Protocol, some Consultative Parties insisted that such regulation is the prerogative of IMO ${ }^{80}$ The IMO is not likely to finalize its work pursuant to the request by the XXVIIth ATCM (2004) before 2007. ${ }^{81}$

Articles 3-8 of Annex IV to the Madrid Protocol deal with the discharge of oil, noxious liquid substances, garbage, and sewage. While some provisions are not intended to create substantive differences with MARPOL 73/78, ${ }^{82}$ many seem to be more stringent. ${ }^{83}$ Several provisions nevertheless lower the stringency level, in particular Article 11 which contains an exemption for "any warship, naval auxiliary or other ship owned or operated by a State and used, for the time being, only on governmental non-commercial service". ${ }^{84}$ While a similar exemption is laid down in Article 3(3) of MARPOL 73/78, its impact is much bigger as a large percentage of the vessels that operate in Antarctica fall in this category. Even though these ships should "act in a manner consistent, so far as is reasonable and practicable" with Annex IV, this leaves a considerable margin of appreciation. Even more problematic is Article 14, which stipulates: "With respect to those Parties which are also Parties to MARPOL 73/78, nothing in this Annex shall derogate from the specific rights and obligations thereunder." This effectively means that the higher level of stringency established by Annex IV to the Madrid Protocol is only applicable to States parties to the Madrid Protocol that are non-parties to MARPOL 73/78 or its Annexes IV and V. This subordination of a lex specialis to a lex generalis is highly unusual. ${ }^{85}$

79 IMO Doc. MSC/Circ.1056-MEPC/Circ.399, of 23 December 2002.

80 Final Report of the XXVIIth ATCM (2004), pp. 22-23 and 28-29, paras 129, 131, 138 and 183-184 and Annex M.

81 See IMO Doc. MSC 79/23, 15 December 2004, 'Report of the Maritime Safety Committee on its Seventy-Ninth Session', at para. 8.25.

82 E.g. Art. 3(1) which simply refers to Annex I to MARPOL 73/78, and Art. 5(1) and (2).

83 E.g. Art. 4, which flatly prohibits the discharge of any noxious liquid substance, and Art. 6(1)(a).

84 See also Arts 3(2), 5(5), 6 and 7(1).

85 Cf. T. Scovazzi, "The Application of the Antarctic Treaty System to the Protection of the Antarctic Marine Environment", in F. Francioni (ed.), International Environmental Law for Antarctica (Milan, Giuffrè Publishing: 1992), pp. 113-134, at p. 132. 
Finally, while the linkages to the Annexes to MARPOL 73/78 are dynamic, in the sense that obligations under Annex IV to the Madrid Protocol are automatically adjusted in accordance with the coming into effect of amendments to MARPOL 73/78, no linkages or substantive overlap currently exist with respect to the 1997 Protocol to MARPOL 73/78 (containing Annex VI on vesselsource air pollution) and to the 2004 IMO Ballast Water Convention. ${ }^{86}$ These developments call for a review of Annex IV to the Madrid Protocol, as is foreseen in its Article 13. ${ }^{87}$

Mention should finally also be made of the Norwegian proposal at the XXVIIth ATCM (2004) to ban the use of heavy fuels south of $60^{\circ}$ South in view of the environmental risks of spills in cold waters. The proposal attracted some support and may be more thoroughly discussed at the XXVIIIth ATCM (2005). ${ }^{88}$ Whereas the proposal seems to focus specifically on the potential environmental impact of heavy fuels due to spills, it would be preferable to focus primarily on the need to limit emissions and thereby air pollution. The latter option could be modelled on relevant regulations in Annex VI to MARPOL 73/78, possibly in combination with a CDME standard. A regulation which would simply ban heavy fuels would be too similar to a ban on the carriage of hazardous cargoes. Discussions on the latter topic within IMO and UNEP have time and again lead to a deadlock between coastal and flag States. The position of the latter is not insignificantly influenced by military interests.

Regulation Outside the ATS

Direct Regulation

Intergovernmental Regulation

The most appropriate point of departure for an examination of direct intergovernmental regulation of tourism is the WTO, which became a specialized agency of the UN in 2003. The establishment and the work of the WTO's Sustainable Development of Tourism Committee and its World Committee on Tourism Ethics as well as the adoption of its Global Code of Ethics for Tourism indicate that the objectives of the WTO have evolved and now encompass the need for balancing the promotion and development of tourism against environmental protection. The WTO is not a typical regulatory authority but instead seeks achievement of its objectives by stimulating international cooperation, public-private integration and the transfer of tourism know-how to developing countries, improving capacity building and education and providing guidance by means of publications (e.g. on sustainable tourism indicators or compilations of best practices) and the Global Code of Ethics for

86 International Convention for the Control and Management of Ships' Ballast Water and Sediments, London, 13 February 2004. Not in force, IMO Doc. BWM/CONF/36, of 16 February 2004. See inter alia Art. 2(9), which relates to "areas beyond the limits of national jurisdiction" and Regulation C-1 'Additional Measures'.

87 See Final Report of the XXVIIth ATCM (2004), at p. 23, para. 134, which refers to the 2004 IMO Ballast Water Convention.

$88 \mathrm{Ibid}$. at paras 135 and 138 . 
Tourism. This Code is one of the few (non-legally binding) instruments adopted by the WTO. The WTO, together with the United Nations Environment Programme (UNEP) and several environmental NGOs (the Rainforest Alliance and the International Ecotourism Society), is also involved in establishing a 'Sustainable Tourism Stewardship Council' tasked with bench-marking and certification of sustainable tourism. ${ }^{89}$

The WTO does not specifically focus on Antarctic tourism. It has, for instance, not established a regional Commission on Antarctica or included Antarctica in one of the existing six Commissions. But the Arctic is treated similarly. The only WTO instrument that specifically relates to Antarctic tourism is the Declaration on Antarctic Tourism made by the WTO Executive Council on 1 December 1998. The general wording suggests that it was mainly prompted by the convening of the fifty-ninth session of the Executive Council in Ushuaia. The XVIth ATCM (1991) for the first time invited the WTO to attend as an expert. It accepted the invitation and even submitted a short information paper. ${ }^{90}$ Since then, however, the WTO participated in only one other ATCM, ${ }^{91}$ even though it was and, presumably will, always be invited.

Other relevant sources of intergovernmental regulation are the Convention on Biological Diversity (CBD), ${ }^{92}$ the Commission on Sustainable Development (CSD), UNEP and The World Conservation Union (IUCN). As most States will regard Antarctic sea-borne tourism as something that takes places beyond the limits of national jurisdiction, ${ }^{93}$ only the CBD's obligations on processes and activities contained in Articles 3, 5, 7(c) and 8(1) are applicable and these lack specificity. As part of the CBD's implementation process, 14 CrossCutting Issues have been identified, one of which is 'Biological Diversity and Tourism'. This has culminated in the adoption of the 'Guidelines on Biodiversity and Tourism Development' in 2004. ${ }^{94}$ The Guidelines are voluntary but cover "all forms and activities of tourism", including ecotourism and cruise tourism. ${ }^{95}$ It seems that the "Framework for management of tourism and biodiversity' set out in Section B of the Guidelines could be useful guidance to ATCMs when deliberating the need for further intergovernmental regulation of Antarctic tourism.

The drafting of the Guidelines was carried out in cooperation with UNEP and the CSD, pursuant to the latter's Decision 7/3 (1999) on 'Tourism and

\footnotetext{
9 Info at <www.rainforest-alliance.org/programs/sv/stsc.html $>$.

Cf. Tracey, note 6, at p. 164.

At the XXIInd ATCM (1998).

2 Nairobi, 22 May 1992. In force 29 December 1993, 31 International Legal Materials 822 (1992); <www.biodiv.org>. 
sustainable development, ${ }^{96}$ which includes an action-oriented international work programme on sustainable tourism development. Calls for various forms of action are directed at governments, the tourism industry and the international community. The UN General Assembly had requested the CSD to develop such a programme and also proclaimed the year 2002 as the International Year of Ecotourism. UNEP is the lead agency responsible for the implementation of Agenda 21-issues on tourism and is, together with the WTO, the main focal point for sustainable tourism within the CSD and the CBD. Other relevant UNEP achievements include its 'Principles on Sustainable Tourism' and fostering multi-stakeholder partnerships and voluntary initiatives (e.g. the 'Tour Operators Initiative for Sustainable Tourism Development'). ${ }^{97}$ As regards IUCN, various publications and the work of the Task Force on Tourism \& Protected Areas established in the framework of the World Commission on Protected Areas (WCPA) are of relevance as well. The Antarctic Advisory Committee (AAC) seeks to coordinate the various objectives of IUCN entities. IUCN obtained expert status at the XIVth ATCM (1987) and has attended all ATCMs ever since. ${ }^{98}$

While the mandates and work of these international bodies varies, ${ }^{99}$ in the context of this article it is important to note that none of the output is very prescriptive $^{100}$ and none relates specifically to Antarctica. Individual States therefore have a wide margin of discretion in regulating tourism and in deciding how the balance between the different interests captured by the notion of sustainable tourism should be struck. This is a direct consequence of the fact that tourism is a purpose rather than an activity. The discretion of States in regulating tourism is nevertheless constrained by a wide range of international obligations and the competence of various IOs in relation to specific activities.

Industry Self-Regulation

Self-regulation by the tourism industry that is relevant to Antarctic sea-borne tourism is undertaken by a large number of international and national industry NGOs as well as individual tour operators. Whereas IAATO is the most important source of self-regulation, it is by no means the only one and not necessarily always the most stringent. Worth mentioning in this context are the World Travel and Tourism Council (WTTC), the International Federation of Tour Operators (IFTO) and the International Council of Cruise Lines (ICCL). However, their self-regulation is not explicitly focused on Antarctic tourism. Many tour operators involved in Antarctic sea-borne tourism are members of these NGOs as well as of IAATO, ${ }^{101}$ while some are members of one of the

\footnotetext{
${ }_{67}$ Report of the Seventh Session (UN Doc. E/1999/29 (E/CN.17/1999/20)), at pp. 38-48.

${ }_{97}$ Text of the Principles and other info at $<$ www.uneptie.org/pc/tourism $>$.

98 Cf. Herr, note 45 , at p. 101.

99 See also UN Doc. A/58/96, of 18 June 2003, 'Assessments of the results achieved in realizing aims and objectives of the International Year of Ecotourism', Note by the SecretaryGeneral.

100 Cf. Tourism and Biodiversity, note 1, at pp. 25 and 38.

101 E.g. the overlap in membership between IAATO and ICCL, which is particularly striking.
} 
former but not IAATO. Examples of relevant non-IAATO self-regulation are the ICCL's "Cruise Industry Waste Management Practices and Procedures"102 and Green Globe 21, the benchmarking and accreditation scheme for sustainable tourism developed by the WTTC. Also, self-regulation by individual tour operators may be more stringent than that agreed to within industry NGOs.

IAATO was formed in 1991 by seven Antarctic tour operators to ensure high quality tourism as well as to influence and pre-empt national and ATS regulation. ${ }^{103}$ As of 1 July 2004 membership had risen to $70 .{ }^{104}$ As part of the shift towards greater transparency and legitimacy of the ATS, and in recognition of IAATO's expertise, it was ad hoc invited to attend the XVIIth ATCM (1992). It has since been invited to all subsequent ATCMs. While the Pacific Asia Travel Organisation (PATA) was also invited to the XVIIth ATCM (1992), it has not played a very active role since then. ${ }^{105}$ PATA was invited to attend an ATCM for the last time at the XXVth ATCM (2002).

Self-regulation by IAATO is achieved in various ways, one of which is the IAATO Bylaws. Whereas the Bylaws are to a large extent concerned with institutional matters, its Article III on Membership contains some of the most important components of self-regulation. Significant limitations in Section A are: not to have more than 100 passengers ashore at any one site at the same time, and that cruise ships carrying more than 500 passengers are not permitted to make any landings. Non-IAATO members may not observe these limitations. ${ }^{106}$ All vessels, whether operated by a member or a non-member of IAATO, try to avoid encounters at scenic locations or landing sites in order to protect the formula of expedition-cruising and the illusion of the Antarctic wilderness. Although this is established practice and not an IAATO rule, it constrains the number of ships and landings at those locations and sites per season. As these constraints are likely to lead to exploring and landing in new areas, this established practice has not just advantages but also disadvantages.

IAATO's self-regulation also occurs through the process by which tour operators' requests for (full) IAATO membership are approved or rejected $v i s-a ̀-v i s$, among other things, the objectives of IAATO and related criteria for membership. ${ }^{107}$ An important component in this process is an observer scheme. In order to qualify for full membership, provisional members must carry an

102 Industry Standard E-01-01 (Rev 2) (text at <www.iccl.org >). See also Johnson, note 5, at pp. 265-266.

103 Cf. Herr, note 45, at p. 105. See also Art. II 'Objectives' of the IAATO Bylaws (text at $<$ www.iaato.org $>$ ).

104 Cf. Doc. ATCM XXVII/IP/68, note 64, at p. 3. For info on membership see $<$ www.iaato. org $>$.

105 Cf. Tracey, note 6, at p. 164.

106 See Doc. ATME 2004 No. 4, 'Tourism and Self-Regulation. A Commentary on IAATO. Submitted by the UK', at pp. 5-6 and the Subsection 'One Form of Unregulated' Tourism below.

107 Art. III, Sections A-C. According to Art. V, Section F, decisions are passed by a two-third majority. 
observer on board one of their trips and the observer's report must confirm satisfactory compliance with the abovementioned objectives and criteria. ${ }^{108} \mathrm{~A}$ related form of self-regulation is the process for assessing whether existing members should be expelled or become probationary members due to noncompliance with the Bylaws. ${ }^{109}$ None of the ATS instruments allow for comparable corrective measures. ${ }^{110}$

IAATO has recently taken the position that the process for obtaining membership is an accreditation process and also uses this terminology. ${ }^{11}$ While there is certainly merit for such a view, the fact that it more or less coincided with proposals by ATCPs for an accreditation scheme suggests it is also motivated by a desire to influence or even pre-empt regulation by the ATS.

The final and most straightforward form of self-regulation is by means of various operating procedures and standards. Among these are the two parts of ATCM Recommendation XVIII-1 (1994). ${ }^{112}$ These were in fact based on guidelines adopted by IAATO in 1991, that were in their turn based on guidelines that were gradually developed since the 1970s by (some of) the operators that eventually founded IAATO. There are several other IAATO operating procedures and standards that are relevant to Antarctic sea-borne tourism. Based on the most recently available documents ${ }^{113}$ these are:

- Ship Scheduling Procedures;

- Marine Wildlife Watching Guidelines (for Vessel and Zodiac operations); ${ }^{114}$

- Operation Guidelines for inflatable boats;

- Underwater Remotely Operated Vehicle (ROV) Guidelines;

- guidelines on various relevant Specialized Adventure Activities, such as sea kayaking, scuba diving and snorkeling;

- Argo/Amphibious Vehicle Operations Guidelines;

108 Art. III, Section A and Doc. ATCM XXVII/IP/69 (2004), 'IAATO's Formalization of an Accreditation Scheme and Internal Audit Process and the Association's Views on an ATCM Accreditation Scheme', at p. 4. A good observer report is not always sufficient. At IAATO's General Meeting in 2004, the membership voted in favour of extending a tour operator's provisional membership for another year despite a good observer report (information provided by D. Landau, 16 September 2004).

109 Art. III, Section H. In 1996, Orient Lines decided to discontinue its membership of IAATO rather than face the possibility of being expelled for continued non-compliance with the 400 tourists-per-vessel limit that was then still applicable. At the time of the decision by Orient Lines, it had the status of Probationary Member due to previous non-compliance with that limit (information provided by D. Landau, 16 September 2004). Non-compliance with any of the IAATO Guidelines can apparently not lead to such consequences.

110 See notes $152-154$ and accompanying text.

111 See Final Report of the XXVIth ATCM (2003), at p. 405 and Doc. ATCM XXVII/IP/69, note 107.

112 See note 39

113 Docs ATME 2004 No. 12, "Overview Summarizing the Terms of Reference. By IAATO", at pp. 8-9; ATCM XXVII/IP/68, note 64, at Appendices F and G; and ATCM XXVII/IP/69, note 107 , at p. 6 and Appendix B. Some of these Guidelines are available at $<$ www.iaato. org $>$.

114 Available at <www.iaato.org $>$. 
- Boot and Clothing Decontamination Procedures; ${ }^{115}$

- Guidelines on the Prevention of the Translocation of Alien Species; ${ }^{116}$

- the Emergency Medical Evacuation Response (EMER) Plan; and

- the Emergency Contingency Plan.

These different tiers of self-regulation as well as many other positive contributions by IAATO and its members, ${ }^{117}$ clearly indicate that IAATO is to be applauded for its efforts. IAATO self-regulation is sometimes characterized as setting conditions to, rather than restricting, Antarctic tourist activities. ${ }^{118}$ The 100 and the 500 passengers rules in the Bylaws seem indeed not exclusively motivated by concern for the Antarctic ecosystem but also by practical considerations and market interests. While these rules may not really 'hurt' financially, it cannot be denied that they do benefit the Antarctic ecosystem. It is nevertheless clear that industry self-regulation will be cautious with restrictions that have significant financial implications unless necessary in view of scientific data, calls by the public and/or governments at the national or international level.

Even though appreciation for IAATO's work should be the point of departure, there is always room for improvement. While the added value of IAATO's self-regulation is presumed, a lack of transparency impedes the verification of this presumption. For instance, not all the texts of IAATO's operational procedures and standards are freely available. ${ }^{119}$ The same is true for reports of IAATO meetings, if they in fact exist, which would be able to shed more light on the processes by which IAATO's operational guidelines are adopted and reviewed, the processes that deal with applications for membership and the processes on compliance for existing members. ${ }^{120}$ Wider participation for non-members at IAATO meetings, in particular those sessions that

115 Title based on Doc. ATME 2004 No. 12, note 112, at p. 8. Docs ATCM XXVII/IP/68, note 64, and ATCM XXVII/IP/69, note 107, use different terminology, for instance "Boot and Clothing Decontamination: IAATO's Recommended Guidelines".

116 Title based on Doc. ATME 2004 No. 12, note 112, at p. 8. Doc. ATCM XXVII/IP/68, note 64, at Appendix G is entitled: 'Introduction and Detection of Diseases in Antarctic Wildlife: IAATO's Perspective' and ATCM XXVII/IP/69, note 107, at p. 7 refers to 'Disease protocol'.

117 See note 62 and accompanying text.

118 Cf. K. Bastmeijer and R. Roura, "Regulating Antarctic Tourism and the Precautionary Principle", American Journal of International Law (forthcoming).

119 At the IAATO website (<www.iaato.org $>$ ) only ATCM Recommendation XVIII-1(1994) and the Marine Wildlife Watching Guidelines are available. As regards the Boot and Clothing Decontamination Procedures and the Guidelines on the Prevention of the Translocation of Alien Species, it is unclear whether Appendices F and G of Doc. ATCM XXVII/IP/68, note 64, contain the texts or merely descriptions of these. The author requested the IAATO Secretariat copies of other operational procedures and standards but his request was turned down because it was not "always in IAATO's interests to share everything we do" and because there would be no "control on how they will be used" (correspondence with D. Landau, August-September 2004).

120 Doc. ATME 2004 No. 12, note 112, at p. 8 acknowledges for instance that the guidelines for Specialized Adventure Activities have been developed by companies offering these 
deal with the abovementioned processes, would further increase transparency. Such improvements would be especially welcome in view of the crucial role which lack of transparency played in criticism on the ATS (see below). Such improvements would seem in fact one of the main requirements in case IAATO's role within the ATS is further strengthened, for instance as part of the proposed accreditation scheme (see below).

As Arctic sea-borne tourism has associated risks similar to those in the Antarctic and as many vessels operate at both poles, Norway and the World Wide Fund for Nature (WWF) approached IAATO to advocate an Arctic counterpart of IAATO, which eventually led to the establishment of the Arctic Expeditions Cruise Operator's Organization (AECO) in October 2003. ${ }^{121}$ AECO is expected to co-ordinate and represent industry interests as well as ensuring high quality tourism. So far its membership stands at around six tour operators. As most of these are also members of IAATO, the latter is likely to be used as a model. ${ }^{122}$ However, the regulatory context in which AECO operates is fundamentally different from that of IAATO. The absence of a land-mass on the north-pole rules out unilateral territorial jurisdiction. Moreover, many of the Arctic tour operators offer tours in and from the Svalbard archipelago, over which Norway was recognized to have sovereignty pursuant to the 1920 Svalbard Treaty. ${ }^{123}$ While Norway is favorably disposed towards industry selfregulation, it can and does impose (legislative) requirements where it deems necessary. ${ }^{124}$ In view of the linkages between Antarctic and Arctic tourism and the fact that certain forms of regulation have extra-territorial effects, ${ }^{125}$ for instance CDME standards, there is a need for harmonization and therefore cooperation at industry-level as well as at governmental level.

\section{Indirect Regulation}

The main form of indirect regulation of Antarctic sea-borne tourism outside the ATS is shipping. ${ }^{126}$ At the intergovernmental level, the regulatory mandate of IMO extends to maritime safety, vessel-source pollution and maritime security in international merchant shipping. Within the IMO, States agree on a wide range of discharge, emission and CDME standards, navigational measures (ships' routeing systems, ship reporting systems [SRSs] and vessel traffic

cont.

activities. This seems to suggest that these guidelines have not been formally adopted by IAATO as a whole.

121 Information provided by D. Landau, 16 September 2004.

122 Cf. Doc. ATME 2004 No. 24, "Polar Tourism: Experience Gained and Lessons Learned from Svalbard. Submitted by Norway", at p. 14.

123 Treaty on the Status of Spitsbergen, Paris, 9 February 1920. In force 14 August 1925; 2 League of Nations Treaty Series 8.

124 Doc. ATME 2004 No. 24, note 121, at p. 15. See also Cruise Tourism on Svalbard-A Risky Business?, WWF International Arctic Programme, 2004; available at $<$ www.panda.org/arctic $>$.

125 See also the discussion at note 33 and accompanying text.

126 The regulation of whalewatching as currently carried out by the IWC is not discussed. 
services [VTSs]), operational and management practices and liability and compensation regimes. These are laid down in a wide range of legally binding and non-legally binding instruments whose scope of application is in general global, thus encompassing the Southern Ocean. ${ }^{127}$

In line with its mandate, IMO's regulatory effort is inter alia aimed at preventing or limiting most of the human safety and ecosystem risks of shipping that were identified above, at ensuring contingency planning and emergency response capability and to provide compensation for damage and harm sustained. In recent years, the IMO bodies with competence to approve protective measures against ecosystem risk have shown to be both pragmatic and open-minded. This is reflected in the adoption of the SRS aimed at avoiding ship strikes of the north Atlantic right whale off the Atlantic coast of the United States and the no-anchoring area to protect the coral reefs in the Flower Garden Banks Marine Sanctuary in the United States EEZ in the Gulf of Mexico. ${ }^{128}$

In the context of maritime safety, the most important ${ }^{129}$ IMO instruments are the 1974 International Convention for the Safety of Life at Sea (SOLAS 74), the 1993 International Management Code for the Safe Operation of Ships and for Pollution Prevention (ISM Code), the 1974 Athens Convention relating to the Carriage of Passengers and their Luggage by Sea (PAL 74), the 1979 International Convention on Maritime Search and Rescue (SAR 79) and the 1996 International Convention on Liability and Compensation for Damage in Connection with the Carriage of Hazardous and Noxious Substances by Sea (HNS 96). Whereas SOLAS 74 contains mainly CDME standards, PAL 74 and HNS 96 provides for liability and compensation regimes and SAR 79 establishes a framework for SAR for the entire globe. The area south of $60^{\circ}$ South is divided into five SAR areas, where SAR responsibility rests with Argentina, Australia, Chile, New Zealand and South Africa. ${ }^{130}$ It is worth repeating here that some of the larger cruise ships operating in Antarctic waters are not polar class or ice-strengthened and that the 2002 IMO Guidelines for Ships Operating in Arctic Ice-Covered Waters were not yet applicable to Antarctic waters at the time of writing.

In the context of vessel-source pollution, the most important IMO instrument is MARPOL 73/78. Its Annexes contain discharge, emission and CDME standards in relation to oil (Annex I), noxious liquid substances in bulk (Annex II), harmful substances carried by sea in packaged form (Annex III),

127 For an overview see <www.imo.org>. See also E.J. Molenaar,Coastal State Jurisdiction over Vessel-Source Pollution (Dordrecht Kluwer Law International: 1998), inter alia at pp. 21-27, 36-40 and 60-74.

128 IMO Res. MSC.85(70), of 7 December 1998 (IMO Doc. MSC 70/23, pars 11.36-11.42 and Annex 16) and IMO Doc. MSC 73/21, of 14 December 2000, pars 11.7-11.8 and Annexes 20-21 respectively.

129 For a comprehensive overview of IMO instruments see <www.imo.org $>$.

130 Information obtained from the Australian Maritime Safety Authority, 18 March 2004. 
sewage (Annex IV), garbage (Annex V) and air pollution (Annex VI). The Antarctica area (south of $60^{\circ}$ South) is designated as a Special Area under Annexes I, II and V, which either limits or prohibits all discharges of these substances, but has not been designated as an SOx Emission Control Area under Annex VI. ${ }^{131}$ In addition, mention must be made of the 2001 International Convention on the Control of Harmful Anti-Fouling Systems on Ships ${ }^{132}$ and the 2004 Ballast Water Convention.

In the sphere of contingency planning and emergency response, the 1990 International Convention on Oil Pollution Preparedness, Response and Cooperation (OPRC 90) as well as its 2000 Hazardous and Noxious Substances (HNS) Protocol must be mentioned. Whereas various conventions on liability and compensation for environmental damage caused by oil and other substances have been developed within IMO, the only pollution damage covered by these conventions is that which occurs in a party's coastal maritime zones. The applicability of these conventions in Antarctica is therefore affected by the controversial issue of coastal States in Antarctica. ${ }^{133}$

As a consequence of IMO's re-affirmed competence in maritime security matters, a diplomatic conference held in December 2002 adopted various amendments to SOLAS 74 and adopted the International Ship and Port Facility Security Code (ISPS Code). Upon the ISPS Code's entry into force on 1 July 2004, many port authorities have introduced a new per capita fee for persons embarking at port in order to recoup the costs of security inspections. As maritime security inspections are probably not carried out on the Antarctic continent, the cost-increase for Antarctic sea-borne tourism relates mainly to the gateway ports and the sub-Antarctic islands.

Whereas the IMO is the main source for the regulation of shipping (and thereby indirect regulation of sea-borne tourism), classification societies, insurance companies and self-regulation by the shipping industry in general or the cruise industry in particular also play a significant role in the maritime safety and environmental performance of shipping. Classification societies such as Lloyd's Register and Det Norske Veritas inspect ships to assess compliance with various standards, partly to establish a 'rating' for insurance purposes. High performance/low-risk vessels secure lower insurance rates. At the time of writing, the International Association of Classification Societies (IACS) was finalizing the development of the IACS Unified Requirements for Polar Ships, which are intended to complement the 2002 IMO Guidelines for Ships Operating in Arctic Ice-Covered Waters and, eventually, their Antarctic counterparts. ${ }^{134}$ Self-regulation of the shipping component of sea-borne tourism is

31 Cf. Molenaar, note 126, at pp. 434 and 569.

132 London, 5 October 2001. Not in force, IMO Doc. AFS/CONF/26, of 18 October 2001.

33 See R. Lefeber, "The Legal Need for an Antarctic Environmental Liability Regime", in Vidas, note 25, pp. 181-197, at pp. 192-193. See also the Final Report of the XXVIth ATCM (2003), paras 91-97 and 104-105.

134 Information provided by R. Hayward, 17 September 2004. 
pursued by individual companies ${ }^{135}$ or by groupings of companies involved in sea-borne tourism in general (e.g. the ICCL) or Antarctic tourism in particular (i.e. IAATO).

\section{The International Legitimacy of the ATS}

The notion of legitimacy is fundamentally different from legality, which concerns the legal validity of a norm and behavior relative thereto. ${ }^{136}$ According to Franck, legitimacy comprises, first "a property of a rule or rule-making institution which itself exerts a pull towards compliance on those addressed normatively" and, second, "the perception of those addressed by a rule or a rule-making institution that the rule or institution has come into being and operates in accordance with generally accepted principles of right process" ${ }^{137}$ The legitimacy of an international regime like the ATS could therefore be perceived as "its persuasive force, as manifested in the level of applicability and acceptance". ${ }^{138}$ Often, but certainly not always, greater legitimacy tends to enhance effectiveness and vice versa. The effectiveness of an international regime is regarded as the extent to which the regime has contributed to solving the basic problems it addresses. ${ }^{139}$

The legitimacy problems of the ATS are a direct result of the unresolved question of sovereignty over Antarctica. ${ }^{140}$ While the 'agreement to disagree' on this question was an acceptable compromise between the claimant States and the few non-claimant States that were invited to the conference that culminated in the Antarctic Treaty, the regime that emerged did not declare Antarctica as a global commons or the common heritage of mankind. Moreover, the lack of clarity and the presence of many undefined terms in the criterion in Article IX(2) of the Antarctic Treaty that has to be satisfied in order to obtain consultative status (see below), were used to bar participation in decision-making and the negotiation of new regimes. ${ }^{141}$ Criticism at the 'Antarctic club' of ATCPs eased after 1977 when the number of Consultative Parties gradually increased. ${ }^{142}$ Eventually even States that had been fierce opponents, like China

135 See, for instance, the decision by Royal Caribbean Cruises Ltd. to install advanced wastewater purification technology (press release of 5 May 2004 at <northamerica.oceana.org $>$ ).

136 See O.S. Stokke and D. Vidas "Effectiveness and Legitimacy of International Regimes", in Stokke and Vidas, note 18, pp. 13-31, at p. 20

137 T.M. Franck, The Power of Legitimacy Among Nations (New York/Oxford, Oxford University Press: 1990), pp. 16 and 19.

138 Stokke and Vidas, note 135, at p. 31

139 Ibid., at pp. 15, 26 and 31.

140 See also Vidas, note 18 , at pp. $48-58$.

141 See for instance F.M. Auburn, Antarctic Law and Politics (Bloomington, Indiana University Press: 1982), at pp. 115 and 147-153. A. Bos, "Consultative Status under the Antarctic Treaty: Redefining the Criteria?”, in A. Jørgensen-Dahl and W. Østreng (eds) The Antarctic Treaty System in World Politics (Macmillan/The Fridtjof Nansen Institute: 1991), pp. 335-342, at p. 335 also notes the limited participation in the conference that eventually adopted the Antarctic Treaty.

142 The procedure adopted at the 1st Special ATCM (1977), has been replaced by ATCM Decision 2 (1997) 'Consultative Status', which inter alia refers to Art. 22(4) of the Madrid 
and India, also obtained consultative status. ${ }^{143}$ In 1983, attendance at ATCMs was opened to Antarctic Treaty parties that were not ATCPs and not long thereafter they were also invited to attend the negotiations on CRAMRA and the Madrid Protocol. ${ }^{144}$ Furthermore, outsiders' concerns on the equitable sharing of Antarctic marine living resources eventually proved unfounded in view of the essentially open-access and ecosystem-oriented character of the CCAMLR Convention. ${ }^{145}$

In 1982, however, when many developed States refused to accept the way in which the principle of the common heritage of mankind was given effective content in the regime for deep sea-bed mining in Part XI of the LOS Convention, ${ }^{146}$ despite the Convention's package-deal character, and negotiations on CRAMRA commenced, legitimacy was again under pressure. ${ }^{147} \mathrm{~A}$ group of developing States led by Malaysia managed to bring the 'Question of Antarctica' on the agenda of the UNGA in 1983. ${ }^{148}$ From 1989 onwards, support for involvement by the UNGA gradually lessened as the legitimacy of the ATS improved. That year Australia and France announced they would not sign CRAMRA and New Zealand subsequently indicated that it would not ratify. This set the ATCPs on a course towards the adoption of the Madrid Protocol in 1991. The Protocol designated Antarctica as a natural reserve and incorporated an indefinite ban on mineral resource activities. ${ }^{149}$ Participation in ATCMs was then further broadened to include key NGOs such as The Antarctic and Southern Ocean Coalition (ASOC) and IAATO. ${ }^{150}$ In 1994, the

cont.

Protocol. This stipulates that as soon as the Protocol has entered into force, applications for consultative status will not be acted upon unless the applicant has ratified the Protocol.

143 Cf. Vidas, note 18, at p. 55. For a chronological overview of the status of the Antarctic Treaty see Antarctic Treaty Handbook, note 16, at pp. 16-17.

144 Cf. Antarctic Treaty Handbook, note 16, at pp. 181-184.

145 J.N. Barnes, "The Emerging Convention on the Conservation of Antarctic Marine Living Resources: An Attempt to Meet the New Realities of Resource Exploitation in the Southern Ocean", in J.I. Charney (ed.) The New Nationalism and the Use of Common Spaces (Allanheld, Osmun Publishers: 1982), pp. 239-286 argues at pp. 240, 248 and 265 that ATCPs had an interest in ensuring the acceptability of the CCAMLR Convention for the reason that this would smoothen the negotiations on CRAMRA. It should also be noted that the negotiations on the CCAMLR Convention were in part motivated by a wish to forestall involvement by the FAO (see Auburn, note 140, at p. 206 and Barnes, this note, at p. 245).

146 This eventually led to the adoption of the Agreement relating to the Implementation of Part XI of the United Nations Convention on the Law of the Sea of 10 December 1982 (New York, 28 July 1994. In force 28 July 1996, 33 International Legal Materials 1309 (1994); $<$ www.un.org/Depts/los $>$ ), which erodes much of the original intention of the common heritage principle laid down in Part XI.

147 See inter alia D. Vidas, "The Antarctic Treaty System and the Law of the Sea: A New Dimension Introduced by the Protocol", in Stokke and Vidas, note 18, pp. 61-90, at pp. $74-75$.

148 A/RES/38/77, of 15 December 1983. See in this respect C.C. Joyner, "Antarctica and the Indian Ocean States: The Interplay of Law, Interests, and Geopolitics", 21 Ocean Development \& International Law 41-70 (1990), at pp. 48-49.

149 Arts 2, 7 and 25 of the Madrid Protocol.

150 See more in general Herr, note 45. See also note 97 and accompanying text in relation to IUCN, which is currently no longer strictly an NGO. 


\section{ANTARCTIC TOURISM AND FURTHER INTERGOVERNMENTAL REGULATION 275}

UNGA resolution on the 'Question of Antarctica' was for the first time passed by consensus and acknowledged the merits of the ATS in the governance of Antarctica. ${ }^{151}$ Subsequent UNGA resolutions on the issue would continue to be adopted without a vote. Malaysia accepted the invitation to observe the XXVth-XXVIIth ATCMs (2002-04) and may soon decide to accede to the Antarctic Treaty. ${ }^{152}$ Finally, efforts commencing in the early 1980s to improve transparency and outsiders' access to information as well as the gradual institutionalization of the ATS, leading to the establishment of the Secretariat of the Antarctic Treaty Secretariat in 2003, all benefited the international legitimacy of the ATS.

It is submitted that the international legitimacy of the ATS is currently no longer negatively affected by concerns on the distribution of Antarctic natural resources. The same is largely true for participation in decision-making on the governance of Antarctica. This notwithstanding, the criterion in Article IX(2) of the Antarctic Treaty that has to be satisfied in order to obtain consultative status and the approval role claimed by ATCPs in that regard, still constitutes a clear bar to participation and thereby raises concerns on the 'openness' of the Antarctic Treaty. ${ }^{153}$ Criticism on the 'closed' character of the Antarctic Treaty seems to be exclusively linked to the legitimacy of the ATS, and not its legality. ${ }^{154}$ The criterion stipulates that an entitlement to consultative status exists

during such time as that Contracting Party demonstrates its interest in Antarctica by conducting substantial scientific research activity there, such as the establishment of a scientific station or the dispatch of a scientific expedition.

151 A/RES/49/80, of 15 December 1994.

152 At the XXVIIth ATCM (2004), Malaysia was invited on an ad hoc basis "to observe" the XXVIIIth ATCM (2005) as no agreement could be reached on incorporating a basis for inviting non-parties to the Antarctic Treaty in the Rules of Procedure for ATCMs (see Final Report of the XXVIIth ATCM (2004), at pp. 10 and 35, paras 27-28 and 232). As during the XXVIth ATCM (2003), this was due to opposition from the Russian Federation (see Final Report of the XXVIth ATCM (2003), para. 16). See also Doc. ATCM XXVI/WP/18 (2003) 'The Attendance of Non-Party States at Consultative Meetings: A Proposed Change to the Rules of Procedures of the ATCM (United Kingdom)', at pp. 1-2.

153 See also the Antarctic Treaty Handbook, note 16, at pp. 155-173. However, this approval role also offers an opportunity to exert pressure on the applicant, which can be used in furtherance of the core objectives of the ATS. This occurred when Ukraine applied for consultative status in 2004 and made assurances to investigate past behaviour in the context of CCAMLR (cf. Final Report of the XXVIIth ATCM (2004), at Annex G). Some months later, at the 23rd Annual CCAMLR Meeting (2004), however, many Members of CCAMLR were very disappointed about Ukraine's follow-up of these assurances (see Doc. CCAMLR-XXIII, preliminary version, at paras $10.74-10.82$ ). Note that the procedures for participation in the CCAS (Art. 12) and the CCAMLR Convention (Art. VII(2)(b) and (d)) also raise concerns of openness, but so far these concerns have not been vindicated.

154 Most importantly, there does not seem to be rule of general international law which would give States a right to participate in decision-making in the Antarctic Treaty. See also the discussion on compliance with international trade law and the prohibition on discrimination below. 
There is a considerable disparity between this criterion and the practically unlimited governance mandate laid down in Article IX(1) of the Antarctic Treaty. Also, it took until 1977 for the twelve original signatories to welcome another ATCP. This suggests that even though the original purpose of the criterion may not have been to bar participation, the application of the criterion certainly had that effect. ${ }^{155}$ This is may have been primarily motivated by the wish to protect the agreement to disagree, rather than by the sharing of natural resources. ${ }^{156}$

Consultative status is nowadays more easily obtained than in the early years of the Antarctic Treaty due to a much less stringent application of the criterion. ${ }^{157}$ This notwithstanding, a large group of predominantly developing States that do not have the necessary financial and human resources to achieve the desired level of scientific research are still effectively barred. It could therefore be argued that the practically unlimited governance mandate in Article IX(1) of the Antarctic Treaty should correspond to a participation criterion that is more generally based on a State's genuine interest in and commitment to Antarctica instead of singling out scientific research. Opponents to such a view might argue that a modestly applied scientific research criterion is appropriate evidence of such "interest in Antarctica". In response it can be said that the considerable financial costs for participating as an ATCP, especially now that the Secretariat to the Antarctic Treaty needs to be financed, ${ }^{158}$ in combination with the absence of tangible benefits in terms of resource sharing, are sufficient evidence of a State's interest. It is nevertheless acknowledged that the international legitimacy of the ATS does not necessarily benefit greatly, or at all, from replacing the current scientific research criterion by a more broadly oriented interest criterion. ${ }^{159}$ The same, or more, benefit may be achieved by further improving the involvement and participation by non-ATCPs, whether parties to the Antarctic Treaty or not. ${ }^{160}$

The at times problematic international legitimacy of the ATCPs and the ATS is closely related to the ATCPs' self-assumed responsibility for the governance

155 Vidas, note 18, at p. 46 observes that Art. IX(2) discriminates against ATCPs that were not original signatories because only the former could lose their entitlement to consultative status. However, a procedure to verify this and to strip a State of its consultative status, is not likely to ever be proposed due to the possibility for a single State to block consensus at ATCMs. It is nevertheless acknowledged that discrimination does exist against new entrants.

156 See M. Haron, "The Ability of the Antarctic Treaty System to Adapt to External Challenges", in Jørgensen-Dahl and Østreng, note 140, pp. 299-308, at pp. 302-303.

157 See Auburn, note 140, at pp. 147-153 and the criticism on the criterion by Bos, note 140, at pp. 339-340, among other things on the need to establish a scientific station to meet the criterion. This criticism was addressed at the Xth SATCM (1990), when the (Kingdom of) the Netherlands obtained consultative status despite not having a scientific station.

158 See Attachment 4 to ATCM Decision 2 (2004) 'Financial Considerations for the Secretariat of the Antarctic Treaty', which takes account of the limited funds of developing States.

159 Some States will undoubtedly take the view that this would require an amendment of the Antarctic Treaty pursuant to its Art. XII, which is likely to take considerable time to enter into force.

160 See also note 151. 


\section{ANTARCTIC TOURISM AND FURTHER INTERGOVERNMENTAL REGULATION 277}

of Antarctica and their strict adherence to the principle of pacta tertiis (see below). By emphasizing their responsibility in the governance of Antarctica in pursuance of the international community's interests, the ATCPs sought to counter the erosion of the international legitimacy of the ATS and the threat of involvement by the UN. Placing the emphasis on their self-assumed responsibility also helped to deflect attention from the regulatory competence or mandate they had in fact claimed, even though on an inter se basis and not against third States. ${ }^{161}$ While the ATCPs have never highlighted their responsibility over tourism, its existence can be construed on account of their selfassumed overall responsibility for the governance of Antarctica as well as their self-assumed environmental responsibility pursuant to the Madrid Protocol, which also applies to tourism, and the exercise of a broader competence by means of the various instruments on tourism adopted by ATCMs so far. ${ }^{162}$

UN involvement was also kept abreast by arguing that the ATS and its regulatory efforts were in furtherance of the principles and purposes of the UN Charter and in the interest of mankind. This is an adequate reply in view of the decentralized nature of international law and the absence of hierarchy among not only the various forms/manifestations of international law but also the various international law-making processes (e.g. IOs). Many international bodies with overlapping mandates have formal or informal co-ordination or primacy arrangements that seek to minimize incompatibility. ${ }^{163}$ As a consequence of new developments and changing needs and interests of the international community, both the competence of international bodies and these arrangements are in a constant state of flux. The choice for a particular international body, including dispute settlement bodies, to pursue a particular issue, is therefore often determined by considerations of international policy, politics and 'forum-shopping'.

161 Neither the 1972 CCAS nor the 1964 Agreed Measures for the Conservation of Antarctic Fauna and Flora refer to the responsibility of ATCPs in any way. However, Recommendation IX-2 (1977) 'Antarctic Marine Living Resources' recalls the "special responsibilities" conferred upon ATCPs in respect of the preservation and conservation of living resources in the Antarctic by virtue of Article IX(1)(f) of the Antarctic Treaty. This is essentially repeated in the Preamble to the CCAMLR Convention and complemented by a recognition of the "prime responsibilities" of the ATCPs for the protection and preservation of the Antarctic environment. The "prime responsibility" of ATCPs for the protection of the Antarctic environment is also recognized in Recommendation IX-5 (1977) 'Man's Impact on the Antarctic Environment'. Moreover, the preamble to Recommendation IX-1 (1977) 'Antarctic Mineral Resources' refers to the contribution of the Antarctic Treaty to the purposes and principles of the UN Charter, which can be seen as a response to the challenged legitimacy of the ATS and the threat of involvement by the UN. Recommendation XI-1 (1981) 'Antarctic Mineral Resources', the Preamble to CRAMRA and the Preamble to the Madrid Protocol take a similar approach.

162 D.J. Enzenbacher, "The Regulation of Antarctic Tourism", in C.M. Hall and M.E. Johnston (eds), Polar Tourism. Tourism in the Arctic and Antarctic Regions (Chichester etc., John Wiley \& Sons, 1995), pp. 179-215, at p. 180. Doc. ATME 2004 No. 20/Rev.1 "The Case for Concern about Antarctic Tourism (ASOC)", at pp. 1 and 3 refers to the "seeming duty" and "responsibility" of the ATS.

163 E.g. Art. VI of the CCAMLR Convention, which acknowledges the primacy of the IWC. 
The discontinuation of the push for UN involvement in 1994 can be regarded as an acknowledgment of the primacy or the primary responsibility of the ATS in most direct governance of Antarctica. The flip side of the medal is of course that where this self-assumed responsibility is not adequately discharged, this has a negative impact on the international legitimacy of the ATS. ${ }^{164}$ But the assessment as to whether or not, or to what extent, responsibility has been adequately discharged, is fraught with the same problems as assessing regime effectiveness or performance. These problems include a lack of a generally accepted uniform methodology and difficulties in establishing plausible causal links. ${ }^{165}$ Moreover, while it can be argued that the ATCPs' self-assumed and publicly declared collective responsibility amounts to a legally-binding obligation, it is widely formulated and lacks operational objectives whose attainment could be easily verified. Accordingly, just like legitimacy is a matter of degree, there will be few situations in which there is general acceptance that responsibility has either been completely discharged or not at all. The grey area between these extremes allows ATCPs, non-ATCPs, non-parties to the Antarctic Treaty and NGOs to argue with some justification that responsibility has or has not been met. Arguably, the position of this grey area is shifted somewhat due to the circumstance that Antarctica is seen by many as the last true wilderness on the planet and therefore entitled to a higher level of performance in terms of governance than anywhere else. ${ }^{166}$

The fundamental international law principle of pacta tertiis stipulates that States cannot be bound by rules of international law unless they have in one way or another consented to them. ${ }^{167}$ An important disadvantage of the agreement to disagree in the Antarctic Treaty is that it does not provide or assert a basis under general international law by which non-parties to the Treaty can be bound, with obvious implications for effectiveness of governance. If a form of joint sovereignty or condominium had been opted for instead, this would have offered such a basis. However, even if sufficient support for such a regime actually existed at some stage, this was no longer so by 1959 , when the Antarctic Treaty was negotiated. It has also been argued that the Antarctic Treaty or the ATS as a whole is to be treated as an objective regime, which is capable of creating erga omnes rights and obligations and thereby regulating the conduct of third States. ${ }^{168}$ Whereas the theory of objective regimes

164 See the discussion by A. Jørgensen-Dahl, "The Legitimacy of the ATS", in Jørgensen-Dahl and Østreng, note 140, pp. 287-298, at pp. 293-295.

165 See Stokke and Vidas, note 135, at pp. 14-20 and Jørgensen-Dahl, note 163, at pp. 293-295.

166 See O.S. Stokke and D. Vidas, "Introduction", in Stokke and Vidas, note 18, pp. 1-9, at pp. 5-6.

167 For treaty law see Art. 34 of the Vienna Convention on the Law of Treaties (Vienna, 23 May 1969. In force 27 January 1980, 1155 United Nations Treaty Series 331).

168 B. Simma, "The Antarctic Treaty as a Treaty Providing for an 'Objective Regime'”, 19 Cornell International Law Journal 189-209 (1986), at pp. 192-196 does not share this view but discusses the International Law Commission's earlier draft articles for what would become the 1969 Vienna Convention (note 166), which incorporated the concept of treaties 
belongs to the arena of international law, it relies to a significant extent on universal acceptance and this is also at the heart of the notion of (international) legitimacy which originated within political science. The fact that the ATCPs, and the ATS as a whole, enjoyed limited international legitimacy for lengthy periods of time means that, at least during these periods, there was very little support for invoking the theory of objective regimes. This is corroborated by the fact that the ATCPs have so far strictly observed the pacta tertiis principle. ${ }^{169}$

In this context it must be noted that due to IUU fishing, CCAMLR has increasingly engaged third States (i.e. States non-parties to the CCAMLR Convention). This is done by means of a two-tier approach, whose first tier is the 'Policy to Enhance Cooperation between CCAMLR and Non-Contracting Parties'. ${ }^{170}$ Non-parties with vessels that are involved in relevant fishing are made aware of that fact, are invited to attend Commission meetings, and are requested to provide information on their fishing activities, to stop fishing or to become a member of CCAMLR. The second tier consists of specific measures to deter fishing by non-parties by forcing them to cooperate with or join CCAMLR, or to stop fishing altogether. Measures taken by CCAMLR that are (also) aimed at non-parties include the Catch Documentation Scheme for Dissostichus spp. (CDS) and port and coastal State measures. ${ }^{171}$ The port and coastal State measures essentially involve withholding benefits to foreign vessels, such as landing catch, using port services and obtaining licenses to fish in the maritime zones of a coastal State. These measures rely on generally accepted bases of jurisdiction under international law and thereby respect the pacta tertiis principle.

As the CDS is a trade-related measure, it must comply with international trade law, most importantly the need for trade-related measures not to "constitute a means of arbitrary or unjustifiable discrimination between countries". ${ }^{172}$ So far, there has been no indication that this is not the case, even

cont.

providing for objective regimes. This concept, he argues, was specifically designed for the Antarctic Treaty. See also B.H. Oxman, "Antarctica and the Law of the Sea", 19 Cornell International Law Journal 211-247 (1986), at p. 223 who links erga omnes effects to collective responsibility. See also Doc. ATCM XXI/WP/22 (1997) 'Enhancing Compliance with the Protocol: Departure State Jurisdiction (United Kingdom)', which at pp. 5-6 invokes the objective nature of the ATS.

169 See, inter alia, Art. X of the Antarctic Treaty, Arts X(1) and XXII of the CCAMLR Convention and Art. 13(2) of the Madrid Protocol.

170 Text at <www.ccamlr.org $>$, under 'Catch Documentation Scheme'.

171 The CDS is laid down in Conservation Measure 10-05 (2004), which also contains provisions on port State control (paras 3 and 14). Conservation Measure 10-03 (2002) relates more specifically to port State control. Conservation Measure 10-07 (2003) contains a whole raft of measures that are to be taken once a non-party vessel is placed on CCAMLR's IUU Vessel List, including port and coastal State measures.

172 See the chapeau to Art. XX of the General Agreement on Tariffs and Trade $(1947$; <www. wto.org $>$ ). 
though only a ruling by a dispute settlement body would remove any doubt. It is submitted that the related issues of participation and allocation of fishing opportunities are crucial factors in this assessment. ${ }^{173}$ The provisions of the CCAMLR Convention and the practice of CCAMLR support the view that there is essentially open access for participation as well as allocation. ${ }^{174}$ Moreover, CCAMLR benefits from the essentially unchallenged legitimacy of regional fisheries management organizations (RFMOs) as the preferred vehicles for fisheries management and conservation at the regional level. If, as is argued, the strengthened duty to cooperate with RFMOs, including CCAMLR, has already evolved into customary international law, this would in fact bestow a certain extent of objective quality on the ATS. It is in this context interesting to note that the efforts by the United Kingdom to create a basis for inviting non-parties to the Antarctic Treaty in the Rules of Procedure for ATCMs, are inspired by CCAMLR's approach to non-parties. ${ }^{175}$ These efforts are motivated by the connected objectives of enhancing the international legitimacy of the ATS and addressing third State issues. ${ }^{176}$ There is nevertheless the concern that the process by which non-complying vessels are listed on CCAMLR's IUU Vessel List, which then requires parties to the CCAMLR Convention to take a range of measures against the vessels listed, not only lacks robustness but also discriminates against vessels of non-members of CCAMLR. ${ }^{177}$

Finally, some comments are warranted on the legitimacy of the ATS with regard to the regulatory process of Antarctic tourism so far. Participation in the discussions on the regulation of tourism is essentially open, similar to all other discussions on regulation that have taken place within the framework of the Antarctic Treaty since the adoption of the Madrid Protocol in 1991. Even though they are not entitled to participate in the taking of decisions, nonATCPs, ASOC and IAATO are invited to attend ATCMs as 'Experts from International Organisations' in plenary, working groups, expert meetings and intersessional contact groups (ICGs) and to submit information papers. There are also no obvious concerns for resource sharing, at least not in the sense of

173 For a more general discussion on these linkages in relation to RFMOs see E.J. Molenaar, "Participation, Allocation and Unregulated Fishing: The Practice of Regional Fisheries Management Organizations", 18 International Journal of Marine and Coastal Law 457-480 (2003).

174 See the end of note 152 on the issue of participation. CCAMLR does not allocate fishing opportunities by means of national quotas, but by setting a TAC and closing the fishing season as soon as it becomes clear that and when the TAC will be reached. This is sometimes referred to as an 'Olympic fishery'. CCAMLR does not allocate fishing opportunities in the maritime zones of various sub-Antarctic islands.

175 See note 151

176 See Doc. ATCM XXVI/WP/18, note 151, at p. 2 and Final Report of the XXVIIth ATCM (2004), at p. 10, para. 28

177 At the 22nd Annual CCAMLR Meeting (2003), when CCAMLR's IUU Vessel List was for the first time adopted, the Russian Federation blocked consensus to ensure that none of its vessels would appear on it (Report of the 22nd Annual CCAMLR Meeting (2003), Doc. CCAMLR-XXII, at paras 8.21-8.22 and 8.29-8.57). 
discrimination against non-ATCPs. Even though tourism depends on Antarctica as its resource base, the use of this resource is intended to be exclusively nonconsumptive. However, if the ATCPs eventually agree on certain forms of caps to tourist numbers or capacity, ${ }^{178}$ this means that usage will have to be allocated. Only a few comments are offered here. While the allocation method opted for must be conducive to the overarching objective of equitable allocation, it also needs to take account of the nature of Antarctic tourism and the legal status of Antarctica. In view of the first consideration, the allocation method that is commonly used by CCAMLR is not suitable, as 'Olympic tourism' would compromise the illusion of wilderness. ${ }^{179}$

\section{IUU Sea-Borne Tourism in Antarctica}

\section{The Meaning of the Acronym IUU}

As mentioned in the introduction, the acronym IUU originated in the sphere of the international regulation of marine capture fisheries. Even though the IPOA on IUU Fishing 180 — a non-legally binding international instrument - does not contain a definition of the acronym IUU, paragraphs 3.1-3.4 offer the following guidance on the meaning of the three components:

3.1 Illegal fishing refers to activities:

3.1.1 conducted by national or foreign vessels in waters under the jurisdiction of a State, without the permission of that State, or in contravention of its laws and regulations;

3.1.2 conducted by vessels flying the flag of States that are parties to a relevant regional fisheries management organization but operate in contravention of the conservation and management measures adopted by that organization and by which the States are bound, or relevant provisions of the applicable international law; or

3.1.3 in violation of national laws or international obligations, including those undertaken by cooperating States to a relevant regional fisheries management organization.

3.2 Unreported fishing refers to fishing activities:

3.2.1 which have not been reported, or have been misreported, to the relevant national authority, in contravention of national laws and regulations; or

3.2.2 undertaken in the area of competence of a relevant regional fisheries management organization which have not been reported or have been misreported, in contravention of the reporting procedures of that organization.

178 Doc. ATME 2004 No. 21, note 218, at p. 3 proposes capping total passenger/tourist numbers.

179 See note 173.

180 See note 15. 
3.3 Unregulated fishing refers to fishing activities:

3.3.1 in the area of application of a relevant regional fisheries management organization that are conducted by vessels without nationality, or by those flying the flag of a State not party to that organization, or by a fishing entity, in a manner that is not consistent with or contravenes the conservation and management measures of that organization; or

3.3.2 in areas or for fish stocks in relation to which there are no applicable conservation or management measures and where such fishing activities are conducted in a manner inconsistent with State responsibilities for the conservation of living marine resources under international law.

3.4 Notwithstanding paragraph 3.3, certain unregulated fishing may take place in a manner which is not in violation of applicable international law, and may not require the application of measures envisaged under the International Plan of Action (IPOA).

Paragraphs 3.1.1-3.1.3 indicate that fishing should be regarded as illegal when it contravenes (violates) national or international law. As regards national law, this could be the coastal State, the flag State or the State of nationality of the natural or juridical person contravening the enactment. In the context of the Antarctic continent, ${ }^{181}$ however, contravention of coastal State enactments is, due to the unique sovereignty situation, not really relevant. Some Antarctic claimant States have ensured that some or all of their legislation applies to maritime areas adjacent to their claims. However, this legislation is either exclusively applicable to, or exclusively enforced against, their own nationals. Consequently, in spite of the geographical scope of application of the legislation, it is the principle of nationality which is the determinative basis for this exercise of jurisdiction.

Illegality due to contravention of international law raises very different issues. International law is, as a general rule subject to exceptions, exclusively applicable between sovereign States. Even though a vessel may have acted in a manner inconsistent with a rule of international law to which its flag State is bound: (1) that vessel may not have violated a domestic enactment that incorporates that rule of international law or its purpose; and (2) the flag State does not necessarily incur State responsibility for the vessel's activities because the State's obligations are usually of a more general nature, for instance exercising effective control and jurisdiction over vessels flying its flag. ${ }^{182}$

It is in this context useful to draw attention to Article VII(5)(a) of the Antarctic Treaty, which obliges Parties to give other Parties advance notice of "all expeditions to and within Antarctica, on the part of its ships or nationals, and all expeditions to Antarctica organized in or proceeding from its territory".

181 The situation with respect to sub-Antarctic islands is of course different

182 See, inter alia, Art. 94 of the LOS Convention. 
The primary purpose of this essentially procedural obligation should be interpreted in the wider context of Article VII, which is aimed at ensuring transparency and open access in order to "promote the objectives and ensure the observance of the provisions of" the Antarctic Treaty. ${ }^{183}$

However, the entry into force of the Madrid Protocol ensured that this obligation became more than essentially procedural. The substantive obligations of the Protocol that specifically relate to tourism are qualified by the phrase "for which advance notice is required in accordance with Article VII(5) of the Antarctic Treaty". ${ }^{184}$ It could be argued that this linkage has the effect of making the substantive obligations applicable for each of the four listed capacities by which a party can be involved in an Antarctic expedition: (1) as a flag State, (2) as a State of nationality, (3) as an organizing State, and (4) as a departure (port) State. ${ }^{185}$ International law indeed recognizes that States acting in any of these capacities have a sufficient link with the relevant persons, objects or activities to entitle it to exercise jurisdiction. However, the fact that the issue of jurisdiction in Antarctica has never been resolved, ${ }^{186}$ does not support the view that the linkage to Article VII(5) of the Antarctic Treaty requires parties to the Madrid Protocol to exercise jurisdiction in all four capacities. The practice of States in implementing the Madrid Protocol, which shows that many Parties do not exercise jurisdiction in all four capacities, ${ }^{187}$ also cannot be used in support of this interpretation, even though it does not necessarily contradict it either. ${ }^{188}$ That practice nevertheless clearly illustrates the crucial role of national law in giving effect to rules agreed to at the international level and thereby enabling certain tourism activities to be treated as illegal.

Paragraphs 3.2.1 and 3.2.2 of the IPOA on IUU Fishing deal with unreported fishing activities. In relation to fisheries management, a lack of reporting or inaccurate reporting undermines science-based management, for instance on stock assessments. In the sphere of tourism, a lack of reporting inter alia frustrates (cumulative) impact assessment. The fact that paragraphs 3.2.1 and 3.2.2 use "in contravention of", similar to paragraphs 3.1.1-3.1.3 on illegal fishing and in contradistinction with the use of "consistent" in paragraphs 3.3.1 and 3.3.2 on unregulated fishing, suggests that an activity only qualifies as unreported if it violates a rule agreed to at the national or international level, and that the activity is therefore at the same time also illegal. This means that the observations made above in relation to 'illegal' are relevant as well.

183 Para. (1).

${ }_{184}$ See note 66. It is worth noting that Art. 1 of the draft Annex VI to the Madrid Protocol, note 132 , also uses this phrase.

185 Cf. Bastmeijer, note 14, at p. 119 who also gives more arguments in support of this view.

186 See Arts VIII(2) and IX(1)(e) of the Antarctic Treaty.

187 Bastmeijer, note 14, at pp. 435-437.

188 See also ATCM Resolution 3 (2004). 
Paragraphs 3.3.1, 3.3.2 and 3.4 deal with unregulated fishing activities. These exist in three different forms. The first form of unregulated fishing relates to the pacta tertiis principle. Here, specific international regulation exists but activities are not in contravention or violation of these, and therefore not illegal, due to the fact that the vessel does not have a flag State or its flag State is not legally bound by them. The relevant existing international regulation is therefore not applicable. These activities by 'free riders' are nevertheless "inconsistent" with international regulation as they undermine the objectives and interests of the international community. The flag States under which they are carried out are subjected to various forms of diplomatic and political pressure ${ }^{189}$ and forms of jurisdiction consistent with the pacta tertiis principle.

The second form of unregulated is one in which no specific international regulation exists but where activities are still "inconsistent with State responsibilities for the conservation of living marine resources under international law". The choice for "inconsistent with" rather than "in violation of" or similar wording, emphasizes the distinction with illegal activities. It is submitted that the "State responsibilities" referred to are not necessarily exclusively nonlegally binding commitments made by States but also comprise legally binding obligations. However, these obligations may be couched in such general or voluntary wording that certain specific activities do not necessarily amount to a violation thereof.

The third form of unregulated ensues from paragraph 3.4 read in conjunction with paragraph 3.3.2, which emphasizes that the absence of specific international regulation does not automatically mean that activities are inconsistent with general international law or, it is presumed, "State responsibilities". This is unregulated in its literal sense.

\section{Addressing IUU Sea-Borne Tourism in Antarctica}

\section{General}

As the discussion in the previous subsection shows, 'IUU fishing' is a very broad term that brings together a number of current threats to the sustainability of marine-capture fisheries. A clear strength of the acronym IUU is its acknowledgment of the multi-facetted nature of the problem and, by distinguishing illegal from unregulated, of the consensual nature of international law. This strength may help to mobilize the international community towards a comprehensive and integrated approach, which the IPOA on IUU Fishing advocates in paragraph 9.3. But this strength is at the same time also its weakness. While usage of the acronym is suitable for a framework-instrument like the IPOA or their national or regional counterparts, it is expected to cause confusion at the stage when specific regulatory action needs to be taken. At that time it is indispensable to focus on each of the (sub)forms.

189 See also note 109. 


\section{ANTARCTIC TOURISM AND FURTHER INTERGOVERNMENTAL REGULATION 285}

Even though IAATO refers to "unreported Antarctic tourism", 190 the suitability of using the acronym IUU in the context of Antarctic sea-borne tourism is certainly not evident. In order for it to have a similar mobilizing effect as in the sphere of marine capture fisheries, it must be clear that there is a significant problem with each of its main forms: illegal, unreported and unregulated. As Antarctic sea-borne tourism can in general not be constrained by territorial or coastal State jurisdiction, and as much of the current body of international regulation is non-legally binding, the illegal component is probably relatively insignificant; but not entirely absent. It is also worth observing that while non-compliance with, for instance, IAATO's self-regulation, can never qualify as illegal, this does not necessarily mean that it never triggers corrective mechanisms. ${ }^{191}$

Despite these important reservations, it is submitted that applying the acronym IUU in the context of Antarctic sea-borne tourism has some modest benefits as well. The most significant one is that the need to distinguish between illegal and unregulated requires a high level of analytical accuracy and consistency, which eventually assists in identifying the real problems and the necessary regulatory tools to address these. The following subsection attempts this for one form of unregulated tourism. A second potential benefit is that this analysis may contribute towards a more comprehensive and integrated approach towards regulation, just as in the sphere of marine-capture fisheries.

This article does not attempt to comprehensively assess the need for further intergovernmental regulation of Antarctic (sea-borne) tourism, but merely offers some observations. The next two subsections discuss possible avenues for addressing one form of unregulated tourism. Whereas the first subsection is mainly devoted to identifying the problem, the second examines an accreditation scheme as a possible solution.

An appropriate first step in the assessment of the need for more intergovernmental regulation on Antarctic sea-borne tourism is gathering relevant qualitative and quantitative data. Considerable effort is already devoted to this. ${ }^{192}$ These data will enable various risk assessments, for example on ecosystem effects in relation to heavy bunker fuel or the introduction of alien species. Predictions on future trends in Antarctic sea-borne tourism, for instance due to

190 See Docs ATCM XXVII/IP/63, note 7, at p. 17 and ATCM XXVI/IP/71 (2003), 'IAATO Overview of Antarctic Tourism', at p. 15. See in this context note 190 and accompanying text.

191 See note 108 and accompanying text.

192 See Doc. ATME 2004 No. 1, 'Report of the Intersessional Contact Group Established by the XXVIth ATCM on the Development of a Database on Tourism and Non-Government Activities'. Unfortunately, at the XXVIIth ATCM (2004), despite significant preparatory work, no Decision was taken (Final Report of the XXVIIth ATCM (2004), at p. 27, para 168). See also R. Naveen, Compendium of Antarctic Peninsula Visitor Sites. A Report to the United States Environmental Protection Agency (Oceanites, Inc., 2nd ed., 30 July 2003). 
changes in vessel ownership patterns ${ }^{193}$ or a strong growth in fly-cruising, would have to be integrated into these risk assessments.

It is submitted that the assessment of the need for more intergovernmental regulation can also be viewed as an assessment of the extent in which the ATCPs have adequately discharged their self-assumed responsibility in the governance of Antarctic tourism. ${ }^{194}$ Consequently, while the availability of data and forecasted trends in Antarctic tourism ensures the assessment's robustness and enables informed decision-making, it still requires policy-makers to set priorities and balance a wide range of interests while striving for the overarching policy objective of sustainable Antarctic sea-borne tourism. Political considerations will undoubtedly play a role. For instance, many States are fully aware of the possible impact of the expansion and diversification of Antarctic tourism on the sensitive sovereignty issue in Antarctica and the operation of the ATS and to what extent that supports or undermines their positions. ${ }^{195}$ Land-based tourism using permanent or semi-permanent infrastructure is singled out as particularly relevant in that regard. ${ }^{196}$

The debate on the need for more intergovernmental regulation is expected to be strongly influenced by the fact that despite the steady expansion of commercial tourism in Antarctica for more than three decades, ATCPs have continued to rely strongly on industry self-regulation. This contrasts sharply with the pro-active regimes for sealing, marine living resources and mineral resources that were largely put in place before exploitation commenced. The spectacular increase in tourist numbers in 2003-04 compared to 2002-03 and

193 See Hemmings and Roura, note 24, at p. 18.

194 The observations made in the Section 'The International Legitimacy of the ATS' are therefore relevant here as well.

195 See Doc. ATME 2004 No. 20/Rev. 1, note 161, which observes on p. 3 that "The emergence of a powerful Antarctic tourism industry - a regional facet of what is now the world's largest industry - has sovereignty and wider geopolitical consequences for the ATS." See also C.M. Hall and M.E. Johnston, "Introduction: Pole to Pole: Tourism Issues, Impacts and the Search for a Management Regime in Polar Regions", in Hall and Johnston, note 161, pp. 1-26, at pp. 18-20 and Doc. ATCM XXIV/IP/40, note 26, at p. 3.

196 See Doc. ATME 2004 No. 7, note 13, at pp. 4-6, where New Zealand also refers to the possibility of attempts by natural or juridical persons to create 'property rights'. See also Doc. ATME 2004 No. 17, note 49, at pp. 1 and 3 and the Final Report of the ATME 2004, at paras 34-39, especially for the Chilean view in para. 37 that the ATS does not prohibit building a tourism facility and that Chilean legislation would allow a public facility to be leased or made over as a concession to a tour operator. Headland, note 23, at p. 277 observes that Chile established the first Antarctic hotel (Hotel Estrella Polar) adjacent to its station Teniente Rodolfo Marsh on King George Island in 1982, but discontinued its use in 1992-93. Doc. ATCM XXVII/IP/63, note 7, at p. 10 mentions that the Chilean Aerovias DAP is planning to offer overnight stays at the Frei/Marsh area on King George Island. Doc. ATME 2004 No. 19, "Tourism in Antarctica. Discussion paper submitted by the Federal Republic of Germany", at p. 2 takes the view that "accommodation[s] tourism in Antarctica is not in line with the Antarctic Treaty and the [Madrid Protocol]". At the XXVIIth ATCM (2004) it was decided to defer discussion on land-based tourism to the XXVIIIth ATCM (2005) (Final Report of the XXVIIth ATCM (2004), at p. 30, paras 193-196). 
the forecast for further increases during 2004-05 will highlight this difference even more.

As the overview of existing international regulation above reveals, a large amount of relevant and applicable international regulation already exists, both originating from the ATS and from outside. The existing regulatory framework is very decentralized and fragmented, but this is not uncommon in international law and is partly a consequence of the fact that tourism is really a purpose rather than an activity per se. It is therefore arguable that the need for new substantive rules is limited to filling gaps, for instance CDME standards for Antarctic shipping. ${ }^{197}$ Such an approach is, at the moment, also likely to engender more support among the ATCPs than the development of a (nonincremental) comprehensive regime laid down in a legally-binding instrument. ${ }^{198}$ This is to a considerable extent caused by the protracted negotiations on the liability Annex to the Madrid Protocol. Moreover, some ATCPs take the view that the emphasis should not be on the development of new substantive rules but on enhancing the implementation of existing ones. The push between 1992-94 by some ATCPs for a tourism Annex to the Madrid Protocol may have failed in the face of similar views. ${ }^{199}$

Finally, some argue that even though Antarctic tourism is a legitimate activity, a more fundamental discussion on Antarctic tourism in the ATS to, inter alia, assess the desirability of certain forms and levels of Antarctic tourism in view of, for instance, wilderness and aesthetic values, is still necessary. ${ }^{200}$ This essentially relates to the process by which all relevant factors and interests are balanced with a view to ensuring the objective of sustainable Antarctic (seaborne) tourism. It is submitted that the extent to which the process is perceived as fair, transparent and non-discriminatory, also contributes to the sustainability of the outcome. This is likely to benefit the internal and perhaps even the external (international) legitimacy of the ATS as well. Of particular relevance for the principle of non-discrimination is the application of priority for scientific research pursuant to Article 3(3) of the Madrid Protocol and if and to what extent, regulation would distinguish between governmental and non-governmental activities. ${ }^{201}$

197 This is also the position of the United Kingdom in Doc. ATCM XXVI/WP/23 (2003), note 13. At the XXVIIth ATCM (2004), this position remained largely unchanged even though the United Kingdom supported the accreditation scheme proposed by Australia. The fact that the XXVIIth (2004) has led to the adoption of Measure 4 (2004) and Resolutions 3 (2004) and 4 (2004) is not necessarily indicative of wide support for this 'gap-filling' approach.

198 See Doc. ATME 2004 No. 22, 'Mechanisms for Regulating Commercial Tourism' (submitted by ASOC), which discusses various options for legally-binding instruments, one of which is a Convention for the Regulation of Antarctic Tourism Activities (CRATA).

199 See note 74 and accompanying text.

200 See Hemmings and Roura, note 24, at pp. 21-22; Kriwoken and Rootes, note 23, at pp. 146-147; Bastmeijer, note 28, at p. 118 and Doc. ATCM XXIV/IP/40, note 26, at p. 3 .

201 Se inter alia Richardson, note 25, at p. 78; Hemmings and Roura, note 24, at pp. 15 and 22 and Doc. ATCM XXVI/IP/96 (2003), note 60, at pp. 4-5 for some observations by 


\section{One Form of Unregulated Tourism}

From the perspective of international law, unregulated tourism in the meaning of tourism activities that are not subject to relevant existing international regulation, is the more interesting one. In view of the pacta tertiis principle, the approach by which this problem needs to be addressed is fundamentally different from approaches addressing the problems of illegal, unreported and the other forms of unregulated tourism.

As the ATS has so far relied strongly on industry self-regulation, it is submitted that 'international regulation' should encompass both governmental and industry regulation and both legally binding and non-legally binding regulation. The main subjects in Antarctic sea-borne tourism to which regulation can be applied are vessels, tour operators and tourists. In order to limit the discussion, tourists are not dealt with. The non-applicability of international regulation is perceived as a consequence of their nationality or their membership of IAATO.

In relation to intergovernmental regulation, both legally and non-legally binding, applicability is formed by means of formal adherence or support (for non-legally binding instruments) by States. This cluster of regulation encompasses the Antarctic Treaty, the Madrid Protocol, relevant ATCM Recommendations, Measures and Resolutions and relevant IMO instruments. In order to, once again, limit the discussion, IMO instruments are excluded.

Many vessels that were involved in Antarctic sea-borne tourism in the 2003-04 season and/or that will be so involved in the 2004-05 season, are registered in States that are not party to the Antarctic Treaty (or the Madrid Protocol). According to the United Kingdom this amounted to $30 \%$ unregulated tourism. ${ }^{202} \mathrm{~A}$ significant number of these vessels are registered in the Bahamas, and the remainder in Barbados, Liberia, Malta and Panama. ${ }^{203}$ However, as practically all the Antarctic tour operators using these vessels are based in ATCPs ${ }^{204}$ this offers a suitable alternative basis for jurisdiction. As the United Kingdom did not become party to the Antarctic Treaty or the Madrid Protocol on behalf of any of its overseas territories, vessels registered there ${ }^{205}$ are strictly

cont.

IAATO. Note that the Madrid Protocol already incorporates provisions on sovereign immunity in Art. 11 of Annex IV.

${ }^{202}$ Final Report of the XXVIIth ATCM (2004), p. 10, para. 28.

${ }^{203}$ Doc. ATCM XXVIII/IP/82, note 9 at pp. 13-14.

204 Based on Doc. ATCM XXVII/IP/63, note 7. See also note 207. The two exceptions seem to be G.A.P. Adventures, based in Canada, who plans to use the Liberian registered Explorer, with a capacity of 100 passengers, for 12 voyages in 2004/05; and Philos Expeditions, based in Switzerland, who uses the sailing yacht Philos, with a capacity of 5 passengers. As of 13 December 2003, Annexes I-IV of the Madrid Protocol entered info force for Canada but as of 29 April 2004 Switzerland was not party to the Madrid Protocol (cf. Doc. ATCM XXVII/IP/36, note 19, at Annex 2). The Canadian accession addresses the concerns expressed in Resolution 6 (1999), note 13.

205 According to Doc. ATCM XXVII/IP/63, note 7, at pp. 13-14 and Appendix E, this concerns 
speaking also non-party vessels. Nevertheless, United Kingdom legislation that implements the Madrid Protocol has been made applicable to all relevant overseas territories. ${ }^{206}$

It should nevertheless be recalled that state practice indicates that States parties to the Antarctic Treaty do not necessarily exercise jurisdiction in all of the four capacities mentioned in Article VII(5) of the Antarctic Treaty. ${ }^{207}$ Even vessels flying the flag of a State party to the Antarctic Treaty and its Madrid Protocol may therefore not be fully subject to its provisions. ${ }^{208}$ The uncertainty on the implications of references to Article VII(5) therefore means that relevant ATS instruments may not be applicable to certain Antarctic cruises. Within the context of this article, it is not possible to investigate the current significance of this problem per se and also relatively to, for example, the shortcomings in national implementation of relevant ATS instruments. Equally so, it also cannot be ruled out that this problem may become more significant in the future.

Mechanisms for information exchange such as those established by Resolution 3 (2004) would nevertheless be helpful in identifying problems in concrete cases. ${ }^{209}$ It could also be transformed into a more mandatory mechanism which identifies an overall objective of $100 \%$ regulatory coverage and several operational objectives to resolve absence of regulatory authority in concrete cases. A more structural solution obviously is for parties to the Antarctic Treaty and the Madrid Protocol to broaden the scope of their legislation. As this would decrease the risk of regulatory gaps but increase the risk of multiple competent regulatory authorities, the mechanism proposed could also fulfill a role of coordinating regulation. ${ }^{210}$ This mechanism could moreover be integrated within an accreditation scheme (see below). The latter could also offer a solution to the (possible) problem of non-applicability of IMO and ATS instruments to vessels used for Antarctic sea-borne tourism. ${ }^{211}$ An alter-

cont.

the Discovery registered in Bermuda (operated by a tour operator that is not a member of IAATO) and several sailing vessels/yachts registered in the British Virgin Islands and the Falkland Islands.

206 The Antarctic Act 1994 (Overseas Territories) Order 1995 (Statutory Instrument 1995, No. 1030) extends provisions of the 1994 Antarctic Act, with modifications, to the territories listed in Schedule 2 to the 1995 Order. This list includes the territories referred to in note 204.

207 See note 186 and accompanying text.

208 See Doc. ATCM XXVI/WP/23, note 13, at p. 9, by which the United Kingdom seems to have in mind the Netherlands, whose Antarctic legislation does not apply to vessels registered in the Netherlands (cf. Bastmeijer, note 14, at pp. 136-137 and 430; see also Richardson, note 25, at p. 82). At the time of writing, this concerned in particular the Amsterdam, registered in the Netherlands and operated by the Holland America Line, based in the United States (and, fortunately, subject to the latter's legislation).

209 See also the account by Richardson, note 25, at pp. 81-83.

210 See also Bastmeijer, note 14, at pp. 436-437.

211 "To operate within the parameters of (...) IMO Conventions" is one of IAATO's objectives (Art. II, Section D of the IAATO Bylaws). However, to what extent compliance with IMO 
native solution to addressing the non-applicability of IMO and ATS instruments is a uniform system of port State control. ${ }^{212}$

As regards industry self-regulation, applicability is principally formed by membership of IAATO. It is likely that, since the establishment of the IAATO in 1991, there has always been some Antarctic sea-borne tourism organized by tour operators that were non-members of IAATO. The vessels used include sailing vessels or yachts but also larger vessels carrying large numbers of tourists with or without making landings. In the 2003-04 season the larger vessels operated by non-members of IAATO were: (1) the Asuka, flagged in Japan and now operated by NYK Cruises Co., based in Japan; (2) the Discovery, flagged in Bermuda and operated by Discovery World Cruises Ltd, based in the United States; ${ }^{213}$ and (3) the Marco Polo, flagged in the Bahamas and operated by Orient Lines, based in the United States. ${ }^{214}$

The 2004-05 season saw, in addition to the Discovery and the Marco Polo, two new entrants with large vessels: (1) the Explorer II, also operating under the name Alexander Von Humbolt, flagged in the Bahamas and operated by Abercrombie \& Kent, based in the United States and (2) the Insigna, possibly flagged in the Marshall Islands and operated by Oceania Cruises, based in the United States. Of these, Oceania Cruises is a non-member of IAATO. Together the Marco Polo and the Discovery landed 4,088 tourists during 8 voyages in 2004-05. This is an increase of about 8\% in comparison with the 2003-04 season, when the number was 3,793. A preliminary estimated increase of about $21 \%$ towards 4,950 is expected for 2005-06. The Insigna, which took 669 tourists on a single cruise without landings in 2004-05, is not expected to operate in $2005-06.215$

These figures indicate that the problem of unregulated Antarctic sea-borne tourism as a consequence of non-applicability of IAATO self-regulation is currently already significant and may for various reasons become more significant in the future. One way in which this problem can be addressed is by giving

cont.

Conventions is part of the processes of acquiring membership and of assessing overall compliance is unclear (see notes 107 and 108 and accompanying text). See also the Draft Resolution proposed by the United Kingdom in Doc. ATME 2004 No. 3 'Tourism: Guidelines Related to Shipping. Provisions for Non-Treaty Flagged Vessels. Submitted by the UK'

212 This could be an integrated system for ensuring compliance with standards that address the risks associated with Antarctic sea-borne tourism already discussed, as well as with other relevant standards, for instance those relating to maritime safety and maritime security. See also F. Orrego Vicuña, "Port State Jurisdiction in Antarctica: A New Approach to Inspection, Control and Enforcement", in Vidas, note 25, pp. 45-69 and Richardson, note 25, at pp. 89-90.

213 See also notes 204 and 205.

214 As regards Orient Lines see also note 108. Based on Doc. ATCM XXVII/IP/63, note 7.

215 Doc. ATCM XXVIII/IP/82, note 9, at pp. 13, 15, 22. 
tour operators incentives to join IAATO. The United Kingdom, for example, has for some time been discriminating against non-IAATO members by not permitting them to visit its Antarctic stations and by imposing limitations on visits of South Georgia. ${ }^{216}$ Whereas in relation to Antarctica this policy is based on established practice, ${ }^{217}$ in relation to its sub-Antarctic islands it is based on port and coastal State jurisdiction. It is submitted that this policy of positive discrimination proceeds from the view that IAATO should continue to play a key role in the regulation of Antarctic tourism. ${ }^{218}$ The linkages between these issues and accreditation will become more apparent in the next subsection.

\section{Accreditation}

A proposal for an accreditation scheme seems to have been first submitted by Australia in the run-up to the XXVIIth ATCM (2004). ${ }^{219}$ At that ATCM a substantial discussion did not really take place and it was decided to task an ICG coordinated by the United Kingdom, to "further examine proposals for the development of an accreditation scheme that would add value to existing mechanisms to manage tourist activities in Antarctica" and report back to the XXVIIIth ATCM (2005). ${ }^{220}$ As this process is currently under way, the discussion on accreditation is confined to some core elements and objectives. The lukewarm response to the accreditation proposal at the XXVIIth ATCM could also mean that it will never materialize.

Bearing in mind the above considerations, the core elements of an accreditation scheme for Antarctic tour operators are likely to be the following:

216 See Doc. ATME 2004 No. 4, note 105, at p. 7. The discussion by D.J. Enzenbacher, "Tourism at Faraday Station. An Antarctic Case Study". 21 Annals of Tourism Research 303-317 (1994), at p. 308 suggests that, in relation to stations, this policy has existed since 1993. With respect to South Georgia, the policy of positive discrimination of IAATO members proposed on p. 64 of the Environmental Management Plan for South Georgia (Public consultation paper, February 1999; text at $<$ www.antarctica.ac.uk $>$ ), was put into place in 2000 (information provided by R. McKee, September 2004). Note the special case of the Discovery, registered in Bermuda but operated by a non-member of IAATO. According to Doc. ATCM XXV/IP/30 (2002) 'Chairman's Report from the Aspen Meeting on Antarctic Tourism (IAATO)', at p. 5 more ATCPs exercise a policy of positive discrimination. In view of note 227, this group does not include the United States.

217 See note 39 .

218 See Doc. ATME 2004 No. 21 'What does Regulation of Commercial Tourism Mean? [Submitted by ASOC]', which, at p. 2, severely criticizes this policy by the United Kingdom and thereby, so it seems, also questions the current performance of IAATO and its future need.

219 Doc. ATME 2004 No. 15 'Accreditation of Non-Government Operators. Submitted by Australia'. At the XXVIIth ATCM the following Docs also dealt with accreditation: XXVII/WP/38 (2004) 'Accreditation Scheme for Antarctic Tour Operators (Australia)', XXVII/IP/69, note 107 and XXVII/IP/108 (2004) 'Tourism Accreditation and Inspection under the Antarctic Treaty (ASOC)'.

${ }^{220}$ Final Report of the XXVIIth ATCM (2004), at p. 28, paras 180-181. See Doc. ATCM XXVIII/WP/18 (2005) 'Report of the Intersessional Contact Group on Accreditation Scheme for Antarctic Tour Operators. (United Kingdom)'. 
- A set of standards addressing risks associated with Antarctic tourism that tour operators need to comply with in order to obtain accreditation. ${ }^{221}$ While the various standards that have so far originated within the ATS would be included at any rate, this could be broadened with operating procedures and standards developed by IAATO. 222 Whereas no consideration seems to have been given to including IMO instruments, this would appear worthwhile in view of their relevance to Antarctic sea-borne tourism;

- A mechanism for accrediting Antarctic tour operators after ascertaining compliance or ability of compliance with agreed standards. This task could be carried out by IAATO, the Antarctic Treaty Secretariat, a new body established within the ATS, a body outside the ATS or by an (ad hoc) inspection involving several ATCPs; $; 23$

- A mechanism for ensuring compliance by Antarctic tour operators once they have obtained accreditation, for instance by periodic inspections and corrective mechanisms for non-compliance (e.g. loss of accreditation), ${ }^{224}$

- If accreditation were to be carried out by IAATO or another body outside the ATS, there would be a need for a mechanism to audit the role of the assessor. If the accreditation scheme is amalgamated with the process for obtaining IAATO membership, meaning that accreditation and IAATO membership are effectively the same thing, this audit mechanism should probably be complemented by institutional reform of IAATO. Such reform should ensure that the objectives and operation of IAATO are in keeping with the interests of the ATCPs and those of the international community. ${ }^{225}$

An accreditation scheme based on these core elements would have at least three objectives. The first relates to the rather straightforward improvements in the management of Antarctic tourism that are encapsulated in the above core elements in terms of, inter alia, performance, compliance and coverage.

The second objective builds on the linkages between the self-assumed responsibility of ATCPs and the international legitimacy of the ATS. Accordingly, adequately discharging the self-assumed responsibility for the

221 Doc. ATCM XXVII/IP/108, note 219, at p. 4 refers to the Inspection Checklists under ATCM Resolution 5 (1995) 'Antarctic Inspection Checklists'. See especially Checklist B: 'Vessels within the Antarctic Treaty Area' (text available at <www.ats.org.ar>).

${ }^{222}$ This is for instance suggested in Doc. ATCM XXVI/IP/95 (2003) 'Tourism Issues' (IAATO), at p. 6.

223 The accreditation process suggested by Australia in Doc. ATCM XXVII/WP/38, note 219, does not express a preference for IAATO, even though the suggested process bears many resemblances with the current IAATO processes for obtaining membership. This contrasts sharply with Doc. ATCM XXVII/IP/108, note 219, which does not envisage a role for IAATO but envisages a system of inspection based on Art. VII of the Antarctic Treaty and Art. 14 of the Madrid Protocol as a vehicle for accreditation.

224 See Doc. ATME 2004 No. 10 'Practical Experience of an Observer Scheme for Antarctic and Sub-Antarctic Tourism. Paper Submitted by New Zealand' and Doc. ATCM XXVI/ $\mathrm{WP} / 23$, note 13 , at p. 17 .

225 See inter alia notes $118-119$ and accompanying text. 
governance of Antarctica would strengthen the international legitimacy of the ATS. Whereas there is more often than not a justifiable range of views as to whether responsibility has been adequately discharged, it is submitted that, under the circumstances, bringing an end to the strong reliance on industry self-regulation can be confidentially defended as a minimum requirement. The fact that much if not all of the existing industry self-regulation will simply be copied or transformed into regulation by the ATCPs does not change that fundamental point. As the technical tourism standards in particular will need to be adjusted on a more or less regular basis, it makes sense to utilize the high level of operational expertise that is currently available within IAATO. One option would be to give IAATO an advisory role similar to COMNAP. The decision to equate accreditation with IAATO membership would further integrate IAATO into the ATS. This will ensure a future for IAATO which, inter alia, has the advantage of a single point of interface between the ATCPs and Antarctic tour operators.

The third objective is a corollary to the second. The consolidated or even enhanced legitimacy derived from discharging the self-assumed governance responsibility, provides a justification for tackling the form of unregulated tourism discussed above by means of incentives to become accredited. This could include a policy of positive discrimination and a port State control scheme or enabling consumer pressure through an accreditation logo and wide publicity of the accreditation scheme. The accreditation scheme may also lead to incentives that originate outside the ATS, for instance reduced insurance costs. If IAATO membership is to be equated with accreditation, institutional reform of IAATO will be required to address issues of transparency, participation and discrimination and thereby ensure compliance with international trade law. ${ }^{226}$

Finally, the discussion so far identified a linkage between resource sharing and the international legitimacy of the ATS and thereby implicitly a linkage between resource sharing and addressing unregulated tourism. It was also argued there that it is likely that access to Antarctic tourism will require allocation in the near future. One option would be for IAATO to be given a comanagement role by being given responsibility for the equitable allocation of tourism opportunities within Antarctica. ${ }^{227}$ Provided that the objectives and operation of IAATO are in keeping with the interests of the parties to the

226 See inter alia notes 118-119 and accompanying text. This would address the concerns expressed by ASOC in Doc. ATME 2004 No. 21, note 218, at p. 2.

227 Back in 1994, Enzenbacher, note 216, at p. 308 already advocated that IAATO should assume "responsibility for handling visit requests and coordinating tour ship visits to research stations" while parties to the Antarctic Treaty would set caps. It is worth noting that the opportunities to visit the United States Palmer Station are currently allocated during the annual IAATO General Meetings. Requests for visits by non-members of IAATO are also taken into consideration (information provided by N. Kennedy, National Science Foundation, July 2004). 
Antarctic Treaty and the international community, and that the ATCPs establish guidelines on the method, criteria and process of allocation, there may be advantages in having a body like IAATO perform this task instead of ATCMs.

\section{Conclusions and Observations}

Tourism is not an activity per se, but rather a purpose for which particular activities are undertaken. Accordingly, the regulation of tourism should have two distinct tiers. One of these should strive for the strategic or overarching objective of sustainable tourism by balancing economic, social and ecological interests, for the present as well as the future. For Antarctic tourism, the objective of sustainability also comprises the fundamental purposes and principles of the Antarctic Treaty, in particular the agreement to disagree on sovereignty over Antarctica and the priority of scientific research over other activities. A second tier needs to ensure that the particular activities by which tourism is undertaken, for example shipping, are carried out in a way which is consistent with and contributes to the overarching objective of Antarctic tourism. It is within this tier that the various risks associated with Antarctic (sea-borne) tourism, for instance risks relating to human safety and the Antarctic ecosystem, need to be addressed.

It is submitted that the current regulation of tourism within the ATS does not sufficiently pursue such a two-tier approach. The efforts on tourism of several intergovernmental organizations such as the WTO, the CBD and the CSD, could provide guidance in strengthening the first tier within the ATS. This would also help to highlight the distinction with the second tier.

The overview of the current international regulation of Antarctic sea-borne tourism shows that much relevant regulation already exists, both within and outside the ATS, and at the intergovernmental as well as at the industry level. The suitability of using the acronym IUU (illegal, unreported and unregulated) in the context of Antarctic sea-borne tourism is certainly not evident. In order for it to have a similar mobilizing effect as in the sphere of marine capture fisheries, it must be clear that there is a significant problem with each of its main forms. As Antarctic sea-borne tourism can in general not be constrained by territorial or coastal State jurisdiction and as much of the current international regulation is non-legally binding, the illegal component is probably relatively insignificant; but not entirely absent. Much more significant is one of the forms of unregulated tourism, namely tourism activities that are not subject to relevant existing international regulation, whether due to vessels flying the flag of States that are not parties to the Antarctic Treaty and its Madrid Protocol or due to tour operators that are non-members of IAATO.

A continuing strong reliance by parties to the Antarctic Treaty on industry self-regulation reflects an inadequate discharge of their self-assumed responsibility for the governance of Antarctica and thereby undermines their international legitimacy and that of the ATS. An accreditation scheme such as is 
currently considered would be able to address these fundamental issues, would probably be more appealing to ATCPs with a dislike for comprehensive regimes, and would provide a justification for addressing the form of unregulated sea-borne tourism referred to above, for instance through regional port State control and policies of positive discrimination.

As the accreditation scheme is still under consideration, it is unclear whether or not, or to what extent, IAATO would be involved. IAATO has already expressed its willingness to actively participate in this scheme, depending, presumably, on how the ATCPs define its mandate and prescribe its functioning. A strong role of IAATO seems preferable as it, inter alia, enables tapping into the wealth of operational expertise that is necessary for an ongoing review of tourism standards and it also offers a solution to the need for the equitable allocation of tourism opportunities in Antarctica in the not too distant future. In order to ensure that the objectives and operation of IAATO are in keeping with the interests of the parties to the Antarctic Treaty and the international community as a whole, however, institutional reform of IAATO will be required to address issues of transparency, participation and discrimination. Such reform should also strengthen IAATO's capability to adapt to future developments in the tourism industry, such as changes in the composition of the fleet, in the number and types of tour operators and shifts towards fly-cruises. 
ESTU 20,2_296-305II 11/25/05 10:24 PM Page 296

11/25/05 10:24 PM Page 296
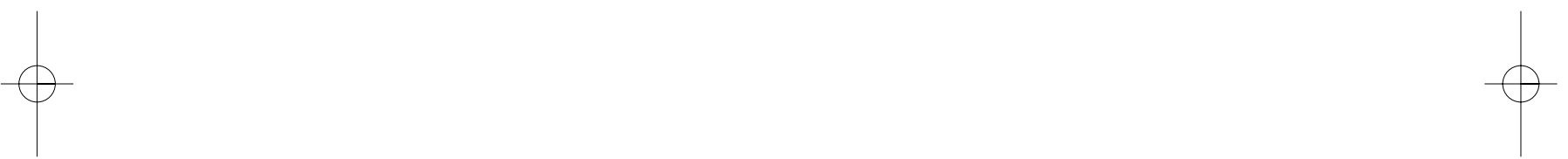